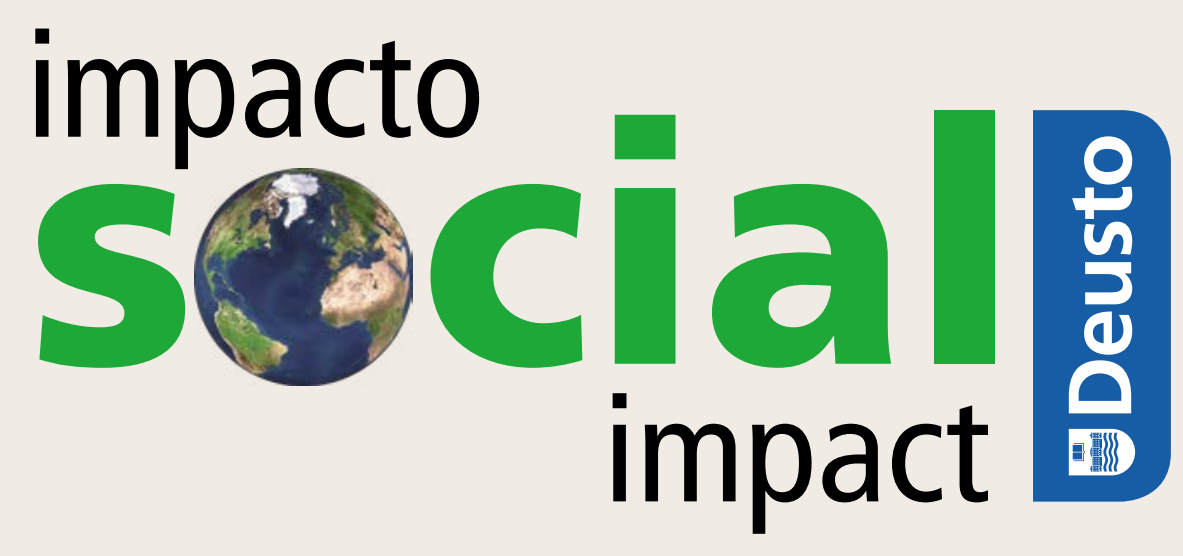

¿Generan estereotipos de género los medios de comunicación? Reflexión crítica para educadores

Do social media generate gender stereotypes? A critical reflection for educators

María Pilar Rodríguez, María J. Pando-Canteli y Miren Berasategi 



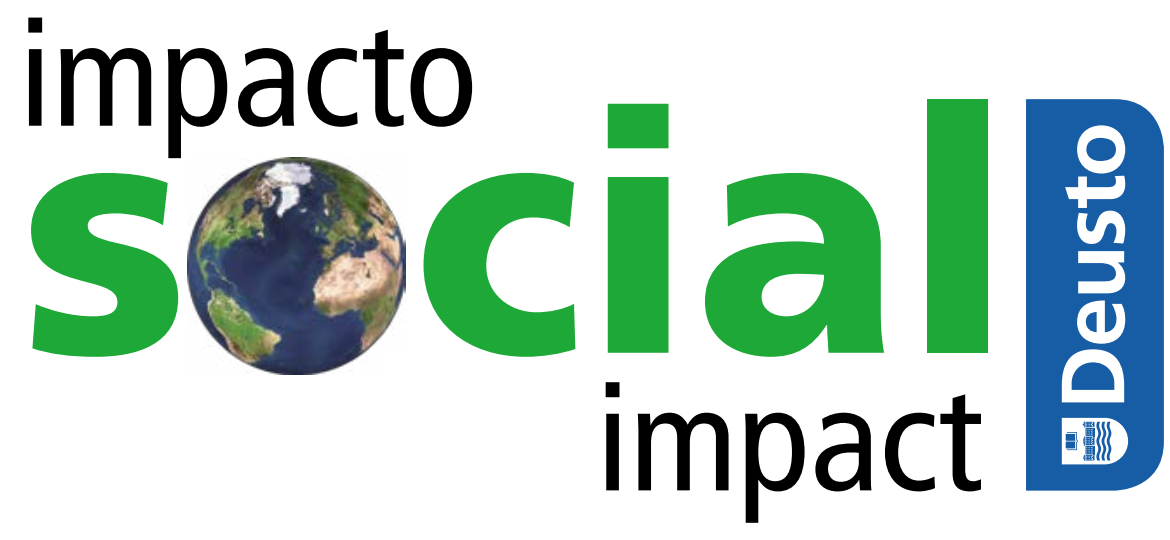


En el marco de la labor llevada a cabo por la Universidad de Deusto (http://www.deusto.es/) en el tema del impacto social de la investigación, anualmente se seleccionan una serie de proyectos de investigación con alto potencial de impacto social, y a partir de ellos, se elaboran y publican los denominados Deusto Social Impact Briefings (DSIB). Son unas monografías breves dirigidas a instituciones sociales, usuarios, policy makers, o empresas que, en lenguaje no académico, responden al objetivo de poner de manifiesto la acción transformadora de la investigación de Deusto, posibilitando que los resultados de la investigación de Deusto sean inteligibles para los agentes sociales y puedan ayudarles a responder a los retos de transformación social a los que se enfrentan, ofreciéndoles buenas prácticas, guías o recomendaciones en la labor que desempeñan.

\section{Frecuencia de publicación y formato}

Deusto Social Impact Briefings se publica electrónicamente y en versión impresa una vez al año. Su primer número se publicó en enero de 2017.

\section{Suscripciones}

Actualmente, no se aplican cargos por la presentación, publicación, acceso en línea y descarga. Pocas copias impresas se ponen a disposición de los colaboradores y socios clave.

\section{Derechos de autor}

Deusto Social Impact Briefings es una publicación de Acceso Abierto de la Universidad de Deusto (España).

Su contenido es gratuito para su acceso total e inmediato, lectura, búsqueda, descarga, distribución y reutilización en cualquier medio o formato sólo para fines no comerciales y en cumplimiento con cualquier legislación de derechos de autor aplicable, sin la previa autorización del editor o el autor; siempre que la obra original sea debidamente citada y cualquier cambio en el original esté claramente indicado. Cualquier otro uso de su contenido en cualquier medio o formato, ahora conocido o desarrollado en el futuro, requiere el permiso previo por escrito del titular de los derechos de autor.
Within the framework of the work carried out by the University of Deusto (http://www.deusto.es/) on the social impact of research, a series of research projects with high potential for social impact are selected annually, and from these, the so-called Deusto Social Impact Briefings (DSIB) are prepared and published as short monographs. They are aimed at social organisations, users, policymakers and businesses. They seek to ensure that research outcomes are intelligible to all these different social actors. They also seek to provide guidelines, best practices and recommendations to support the tasks of meeting the challenges of social transformation that must be faced.

\section{Publication frequency and format}

Deusto Social Impact Briefings is published electronically and in print version once a year. Its first issue appears in January 2017.

\section{Subscriptions}

Currently, no charges for submission, publication, online access, and download are applicable. Few print copies are freely made available for key collaborators and partners.

\section{Copyrights}

Deusto Social Impact Briefings is an Open Access publication of the University of Deusto (Spain).

Copyright for this publication is retained by the Publisher. Any part of its content can be reused in any medium or format only for non-commercial purposes and in compliance with any applicable copyright legislation, without prior permission from the Publisher or the author(s). In any case, proper acknowledgement of the original publication source must be made and any changes to the original work must be clearly indicated. Any other use of its content in any medium or format, now known or developed in the future, requires prior written permission of the copyright holder.

(C) Universidad de Deusto

P.O. box 1 - 48080 Bilbao, España

Publicaciones

Tel.: +34-944139162

E-mail: publicaciones@deusto.es

URL: www.deusto-publicaciones.es

ISBN: 978-84-16982-15-8 (version impresa / printed version)

Deposito Legal/ Legal Deposit: BI-108-2017

Impreso y encuadernado en España / Printed

and bound in Spain 
DEUSTO Social Impact Briefings No. 1 (2016)

Dirección y coordinación editorial

Cristina Iturrioz Landart, Universidad de Deusto, España Antonia Caro González, Universidad de Deusto, España

\section{Comité Cientifico:}

Javier Arellano Yanguas, Director del Centro de Ética Aplicada e investigador principal del equipo «Ética Aplicada a la Realidad Social» (EARS), Universidad de Deusto

Antonia Caro González, Directora de la Oficina de Proyectos Internacionales de Investigación y experta en temas europeos, innovación en gestión de la investigación e impacto social, Universidad de Deusto, España

Laura Teresa Gómez Urquijo, investigadora y Profesora en la Facultad de Derecho e investigadora del equipo Desarrollo Social, economía e Innovación para las Personas (EDISPE), Universidad de Deusto, España

Cristina Iturrioz Landart, Vicerrectora de Investigación y Transferencia e investigadora del equipo de Competitividad Empresarial y Desarrollo Económico (CEDE), Universidad de Deusto, España

Amaia Méndez Zorrilla, Professora en la Facultad de Ingenieria e investigadora del equipo E-vida, Universidad de Deusto, España

José Javier Pardo Izal, Profesor del departamento de Teología e investigador en Teología Bíblica y su influencia cultural, Universidad de Deusto, España.

Rosa María Santibañez Gruber, Profesora en la Facultad de Psicologia y Educación e investigadora principal del equipo Intervención: Calidad de Vida e Inclusión Social, Universidad de Deusto, España

\section{Editors}

Cristina Iturrioz Landart, University of Deusto, Spain Antonia Caro González, University of Deusto, Spain

\section{Scientific Committee:}

Javier Arellano Yanguas, Head of the Centre for Applied Ethics and Main Researcher in the Ethics Applied to Social Reality research team at the University of Deusto, Spain.

Antonia Caro González, Head of the International Research Project Office and expert in European issues, social impact and innovation in research management at the University of Deusto, Spain

Laura Teresa Gómez Urquijo, lecturer at the Faculty of Law and researcher in the Economics, Social Development and Innovation for Persons (EDISPE) team at the University of Deusto, Spain

Cristina Iturrioz Landart, Deputy Rector for Research and Knowledge Transfer and researcher in the Business Competitiveness \& Economic Development (CEDE) team at the University of Deusto, Spain

Amaia Méndez Zorrilla, lecturer at the Faculty of Engineering and researcher in the E-Life team at the University of Deusto, Spain

José Javier Pardo Izal, lecturer at the Department of Theology and researcher working on biblical theology and its cultural influence at the University of Deusto, Spain.

Rosa María Santibañez Gruber, lecturer at the Faculty of Psychology and Education and Main Researcher in the Intervention: Quality of Life and Social Inclusion team at the University of Deusto, Spain 



\section{Prólogo}

Los Deusto Social Impact Briefings (DSIB) son monografías breves que permiten mostrar las capacidades de investigación instaladas en la Universidad de Deusto (http://www.deusto.es/) a través de proyectos de investigación desarrollados por personal investigador de nuestra universidad en las áreas de conocimiento de alta relevancia social. Publicados en papel y online (en castellano e inglés) con una periodicidad anual, se pueden encontrar también en la página web de Deusto Research.

Están dirigidos a entidades sociales, usuarios, policy makers y/o empresas, posibilitando que los resultados de la investigación sean inteligibles para estos diferentes agentes sociales y pretenden, mediante la oferta de buenas prácticas, guías o recomendaciones, apoyarles en la labor que desempeñan para responder a los retos de transformación social a los que se enfrentan.

Dentro del proyecto estratégico Deusto 2018 y en el marco del Plan Director de Impacto Social, el presente briefing fue seleccionado, por su alto potencial de impacto social, a través de una convocatoria lanzada a toda la comunidad investigadora en 2016. Forma parte de un conjunto de cinco briefings resultantes de la mencionada convocatoria y que conforman el primer número de los DSIB.

¿Generan estereotipos de género los medios de comunicación? Reflexión crítica para educadores. Este briefing se basa en años de reflexión sobre la equidad de género y los medios de comunicación y expone ejemplos para que educadores puedan trabajar el pensamiento crítico sobre este tema.

Deseamos disfruten de su lectura tanto como nosotros lo hemos hecho durante la preparación de la publicación; ha sido especialmente gratificante comprobar el grado de implicación y colaboración del personal investigador académico y de los 'stakeholders' en los proyectos.

Esperamos esta publicación cumpla el objetivo para el que ha sido creado, que no es otro que el de hacer la ciencia más accesible, útil y cercana a profesionales, responsables de políticas públicas y agentes sociales que trabajáis en los temas. Agradecemos vuestro interés y estamos abiertos a nuevas iniciativas, así como a comentarios y sugerencias que nos queráis hacer llegar.

Cristina Iturrioz Landart, Dirección DSIB Antonia Caro González, Dirección DSIB

Diciembre de 2016 


\section{Foreword}

The Deusto Social Impact Briefings (DSIB) are brief monographic publications that highlight the research capabilities based at the University of Deusto (http:// www.deusto.es/) through projects conducted by researchers at our University in areas with a high level of social relevance. They are to be published yearly in hard copy and on-line (in both Spanish and English) and can also be found on the website of Deusto Research.

They are aimed at social organisations, users, policy-makers and businesses, and seek to ensure that research outcomes are intelligible to all these different social actors. They also seek to provide guidelines, best practices and recommendations to support the tasks of meeting the challenges of social transformation that must be faced.

As part of the Deusto 2018 strategic project under the Master Plan for Social Impact, this briefing was selected for its high potential social impact, following a call sent out to the whole research community in 2016. It is one of five briefings selected from that call for inclusion in the first issue of the DISB.

Do the social media generate gender stereotypes? A critical reflection for educators. This briefing is based on years of study in the field of gender equity and the media, and provides examples to help educators work with young people on critical thinking in regard to this topic.

We hope that you will enjoy reading its findings and conclusions as much as we enjoyed preparing them for publication. It has been particularly gratifying to observe the high level of engagement and cooperation on the part of academic researchers and the stakeholders involved in the project.

We also hope that this publication will meet the goals for which it was created, i.e. to make science more accessible, useful and readily available to specialists, heads of public sector policy and social actors working in the relevant fields. Thank you for your interest; we are open to new initiatives and would welcome any comments and suggestions that you may care to make.

Cristina Iturrioz Landart, Editor Antonia Caro González, Editor

December 2016 


\section{¿Generan estereotipos de género los medios de comunicación? Reflexión crítica para educadores}

María Pilar Rodríguez, María J. Pando-Canteli y Miren Berasategi

1. Introducción: el poder de los discursos mediáticos en la construc-

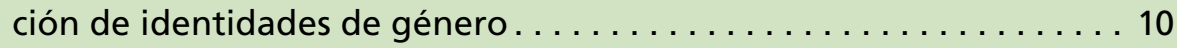

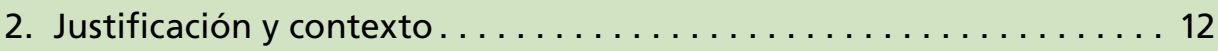

2.1. ¿Por qué es importante analizar los medios con perspectiva de

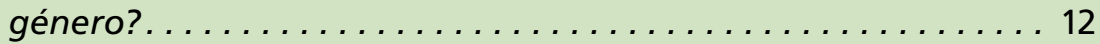

2.2. ¿A quién va dirigido este briefing?............... 13

3. Objeto de estudio: medios de comunicación, publicidad y género . . 15 3.1. Generación de espíritu crítico basado en años de investigación . 16

3.2. Diversos medios de comunicación y su impacto ........... 19

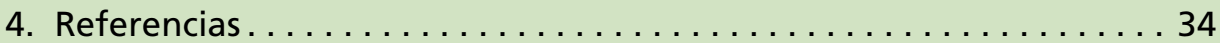

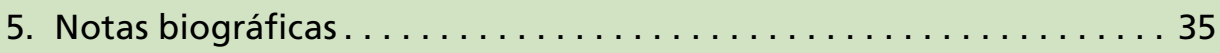





\title{
¿Generan estereotipos de género los medios de comunicación? Reflexión crítica para educadores
}

\author{
María Pilar Rodríguez, María J. Pando-Canteli y Miren Berasategi
}

doi: http://dx.doi.org/10.18543/dsib-1(2016)-pp89-115.pdf

\section{Resumen}

Este briefing expone la importancia de los medios de comunicación en la construcción de las identidades de género. Se muestran ejemplos de la prensa, de la televisión, de la publicidad y de Internet para ilustrar de modo claro y directo la presencia de los estereotipos sexistas y su influencia en la construcción de nuestras imágenes sobre las mujeres y los hombres. Promueve el desarrollo del espíritu crítico para analizar el poder que tienen los discursos mediáticos en la construcción de universos simbólicos de muy fácil consumo, en los que lo femenino y lo masculino ocupan jerarquías muy distintas.

\section{Palabras clave:}

medios de comunicación, género, estereotipos, educación, igualdad.

\section{Abstract}

This briefing highlights the importance of media in the formation and transmission of gender identities. Examples are given from the press, from TV, from advertising and from the Internet to illustrate clearly and directly the presence of sexist stereotypes and their influence on the construction of our images of women and men. The briefing seeks to encourage critical thinking in analysing the power of media discourses in the construction of easily consumable symbolic universes in which the feminine and the masculine occupy very different hierarchical levels.

\section{Keywords:}

media, gender, stereotypes, education, equality. 


\section{Introducción: el poder de los discursos mediáticos en la construcción de identidades de género}

Este briefing expone la importancia de los medios de comunicación en la construcción de las identidades de género. Es el resultado de una reflexión dilatada en torno al poder de los medios de comunicación y su capacidad para producir, perpetuar o modificar pautas de conducta social e imaginarios colectivos.

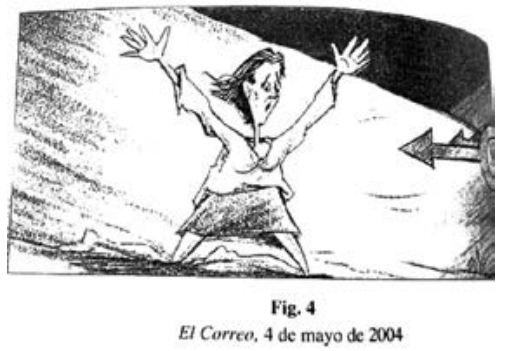

Espera poder contribuir a la sensibilización de la sociedad en general, y del colectivo de educadores y educadoras en particular, sobre el poder que tienen los discursos mediáticos en la construcción de universos simbólicos de muy fácil consumo, en los que lo femenino y lo masculino ocupan jerarquías muy distintas.

Por ello, este trabajo se dirige principalmente a instituciones educativas que han de enfrentarse a la labor diaria de contribuir al desarrollo de competencias críticas en niños/as y adolescentes, especialmente en su exposición permanente a un consumo mediático para el que no existen filtros y para el que no se ha preparado ni a adultos ni a menores.

\section{Con el objetivo de reflexionar}

de forma abierta y proporcionar

instrumentos de análisis

crítico, esta contribución está

especialmente destinada

a concienciar al público en

general y, de manera particular,

a educadores tanto en la

escuela como en la familia

El colectivo de educadores es especialmente relevante porque ha de asumir la imponente responsabilidad de inculcar a quienes constituirán las generaciones futuras los valores y el juicio crítico suficiente para crecer como individuos libres e iguales. Solo así, desde una ciudadanía crítica e informada se pueden combatir las intolerancias y los prejuicios, y se puede ejercer como personas consumidoras responsables, con capacidad real de elección y poder para discernir.

Además, se ofrecen claves para estudiantes y profesionales de la comunicación, sin formación en estudios de género, que están llamados a generar nuevos productos mediáticos críticos con algunos de los modelos existentes.

El objetivo de fomentar la ciudadanía libre, crítica y tolerante subyace en los principios de los sistemas educativos de países democráticos y avanzados. Este briefing persigue ser un espacio de reflexión en torno a la necesidad de una alfabetización temprana en el consumo de medios, como un elemento más fundamental de la educación integral de una ciudadana o un ciudadano en el siglo XXI. 
El análisis en clave de perspectiva de genero puede abordarse desde distintos ángulos (producción, representación, público receptor). Este briefing se centra en lo que se ha denominado representación: cómo se representan hombres y mujeres en los diferentes géneros informativos y soportes mediáticos y qué estrategias subyacen a dicha representación.

Los medios de comunicación son simultáneamente reproductores y creadores de los modelos femeninos y masculinos, es decir, de lo que social y culturalmente es considerado adecuado del ser mujer y del ser hombre. En aspectos fundamentales de la vida social, la mayoría de la población no tiene un conocimiento directo por medio de su experiencia de cuestiones fundamentales ligadas a las construcciones de género y su imagen mental se va elaborando a través de los medios de comunicación. Si bien hoy en día tenemos más datos que nunca y el acceso a la información es directo e inmediato, el conocimiento real requiere un aprendizaje del modo en el que los medios elaboran sus informaciones y de los intereses que en muchas ocasiones subyacen a las noticias, reportajes y artículos de opinión.

\section{Representación:}

Cómo se representan hombres

y mujeres en los diferentes

géneros informativos y soportes

mediáticos y qué estrategias

subyacen a dicha representación

Por tanto, se propone dar a conocer aspectos relevantes de las distintas investigaciones que puedan ayudar a comprender, con ejemplos concretos, cómo se construyen estas representaciones en los diferentes soportes $y, a$ través de un análisis crítico del discurso, identificar los mecanismos que contribuyen a producir estos mensajes. Para ello abordamos el análisis de televisión, prensa, publicidad e internet, desvelando, a través de ejemplos representativos, las formas en las que la prensa, la televisión y la publicidad construyen las noticias, las informaciones y los programas de entretenimiento en función de estereotipos que acentúan la desigualdad.

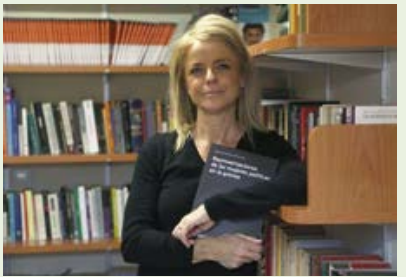
dores de otras facultades de DEUSTO para reforzar su carácter interdisciplinar. 


\section{Justificación y contexto}

La investigación interdisciplinar en los estudios de género y de mujeres ha de descansar necesariamente sobre la premisa básica de que el avance social no solo se logra desde la puesta en marcha de nuevas políticas correctoras o nuevas iniciativas ciudadanas, sino desde la capacidad de generar marcos teóricos nuevos que permitan avanzar en el cambio social. Desde este convencimiento, un modelo integral y bien articulado de cambio social en la lucha por la igualdad, ha de vertebrarse necesariamente en:

- la investigación que revise críticamente los modelos existentes y explore nuevos marcos teóricos;

- la transferencia de ese conocimiento a través de modelos curriculares que transmitan este espíritu crítico de forma transversal;

- y finalmente, la aplicación de este conocimiento en la sociedad mediante acciones concretas que contribuyan a erradicar estas desigualdades.

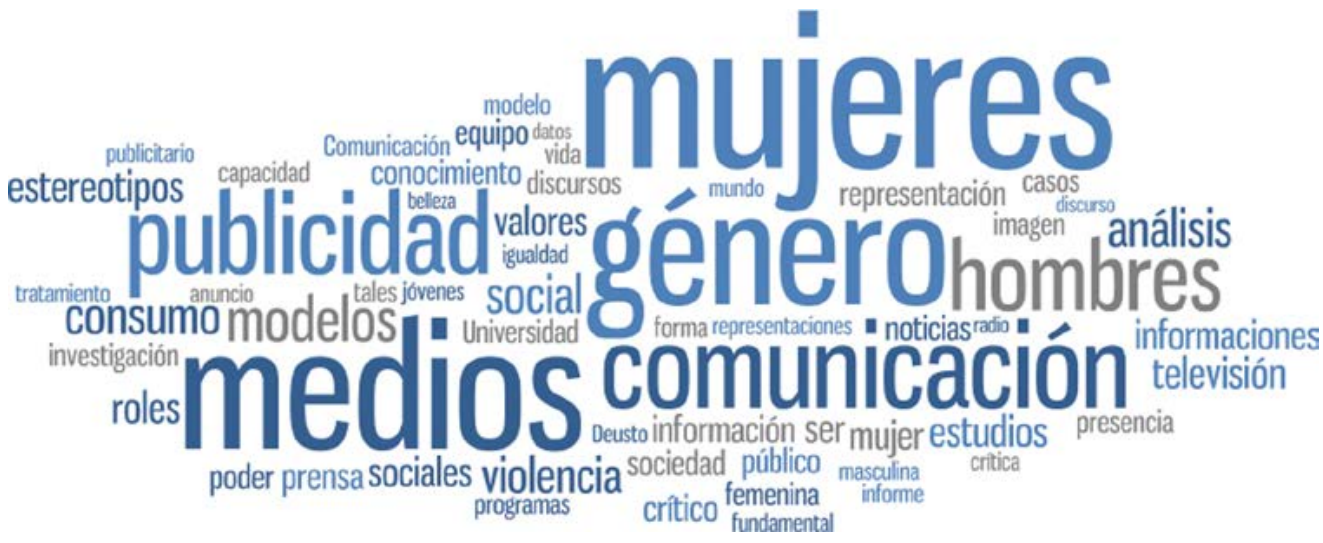

\section{1. ¿Por qué es importante analizar los medios con perspectiva de género?}

Está ampliamente documentado el poder de los medios de comunicación no solo como transmisores sino como productores activos de la realidad. Son industrias e instituciones que actúan en un mercado globalizado pero que entran diariamente en nuestras casas y perfilan nuestro acceso a la representación de las esferas políticas, sociales, económicas y culturales. Los medios de comunicación tienen una gran relevancia en la construcción de la imagen del mundo que se elabora a nivel de imaginario colectivo. La actualidad informativa, el valor de la noticia y su jerarquización en la rutina informativa, el cine, la publicidad de bienes 
La actualidad informativa,

el valor de la noticia y

su jerarquización en la

rutina informativa, el cine,

la publicidad de bienes

de consumo y su ubicua

presencia en la vida diaria

de las personas, todo esto

va construyendo nuestra

realidad diaria, estructurando

nuestra escala de valores y

fijando modelos de conducta de consumo y su ubicua presencia en la vida diaria de las personas, todo esto va construyendo nuestra realidad diaria, estructurando nuestra escala de valores y fijando modelos de conducta. Por eso es fundamental estudiar detenidamente cómo se construyen estos discursos, qué modelos de vida colectiva transmiten y cómo contribuyen a reforzar desigualdades o por el contrario a promocionar modelos de igualdad y de convivencia. Finalmente, hay que señalar que se nos educa para comprender y producir discursos escritos, para enfrentarnos a la codificación y decodificación de un texto escrito, pero no para enfrentarnos críticamente a un mensaje audiovisual complejo, sea éste una noticia en un informativo, un reality show televisivo o un videoclip publicitario.

\section{2. ¿A quién va dirigido este briefing?}

La hegemonía que ejercen los medios de comunicación en la vida diaria de las personas hace que se imponga como una prioridad educativa el conocimiento crítico de la producción y consumo de la información, el entretenimiento y la publicidad. No obstante, los sistemas educativos aún no lo han incorporado a sus desarrollos curriculares en sus diferentes ciclos. Si bien la alfabetización y las competencias de comprensión textual son una prioridad en las enseñanzas primarias y secunda-

La hegemonía que ejercen los medios de comunicación en la vida diaria de los individuos hace que se imponga como una prioridad educativa el conocimiento crítico de los diferentes sistemas que operan en la producción y consumo de la información, el entretenimiento y la publicidad rias, no ocurre lo mismo con la «alfabetización» audiovisual y mediática, a pesar de que la población infantil y juvenil se expone con mucha más frecuencia e intensidad a discursos audiovisuales y digitales que a una comunicación escrita meramente textual.

Falta, por un lado, sensibilización sobre cómo abordar el consumo de medios de comunicación y de productos de entretenimiento $y$, por otro, herramientas educativas en las escuelas y en las familias para enfrentarse críticamente a discursos que con mucha 
frecuencia reproducen desigualdades de todo tipo y exaltan la violencia por encima de niveles tolerables.

En un contexto de consumo globalizado de productos audiovisuales se impone una formación que permita enfrentarse a esta realidad con espíritu crítico, ciudadano y constructivo. Es, por tanto, particularmente importante que educadores y educadoras se impliquen en la tarea.

La conciencia crítica se va creando a través de un proceso que consiste, en primer término, en desvelar las técnicas y procedimientos utilizados por los diversos medios de comunicación para la elaboración de sus informaciones y argumentos $y$, en segundo término, en aplicar las técnicas interpretativas necesarias para comprender la intención subyacente a los mensajes. Esto redunda en una ciudadanía crítica, y ello es el primer paso para una concienciación social que, en último término, puede dar lugar a acciones y proyectos para lograr una sociedad más justa e igualitaria.

La reflexión que propone este briefing contribuye a eliminar efectos indeseados en el consumo de medios de comunicación, tales como el efecto narcótico que se produce con las informaciones repetidas de casos tales como las muertes de las mujeres víctimas de la violencia de género. Es particularmente importante que educadores y educadoras se impliquen en la tarea de formación de niños y niñas y de adolescentes en la adquisición de las destrezas críticas que les capaciten para percibir y cuestionar los discursos racistas, sexistas y discriminatorios en general. En un contexto de consumo globalizado de productos audiovisuales se impone una formación que permita enfrentarse a esta realidad con espíritu crítico, ciudadano y constructivo.

Quien adquiere tal conciencia crítica no solo tiene mejor preparación para involucrarse en actuaciones de compromiso personal encaminadas a que los derechos humanos y la igualdad de género no sean causas perdidas o desdeñadas, sino que podrá ejercitar de forma más sólida sus derechos ciudadanos y contribuir de forma crítica a una sociedad más justa. 


\section{Objeto de estudio: medios de comunicación, publicidad y género}

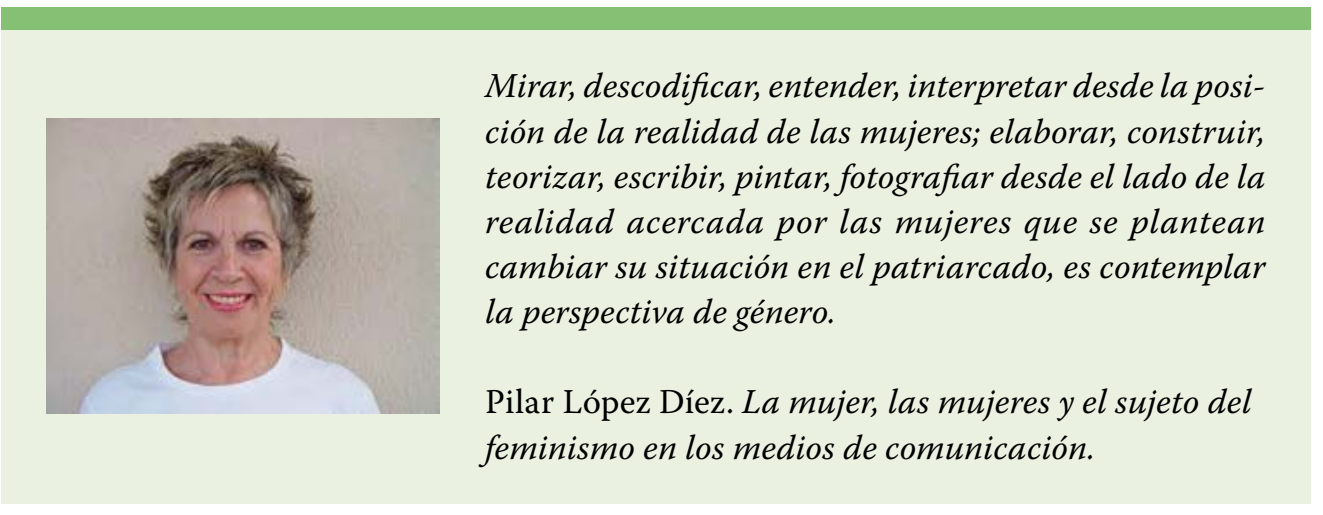

Se estudia la influencia de los medios de comunicación y de la publicidad en la construcción de roles de género ya que son, simultáneamente, reproductores y creadores de los modelos normativos, es decir, de lo que social y culturalmente es considerado adecuado o normativo. Las representaciones estereotipadas afectan al conjunto de la sociedad, tanto a mujeres como a hombres, al transmitir una imagen poco equilibrada, injusta y desproporcionada en muchas ocasiones. Igualmente tienen la capacidad para promover imágenes transgresoras y para cuestionar estereotipos y contribuir a una sociedad más igualitaria. Pero esto no siempre ocurre, ya que con frecuencia tanto los medios de comunicación como la publicidad son resistentes a los cambios de roles y optan por instalarse en modelos fácilmente consumibles.

\section{La mirada masculina se ha socializado como normativa y se resiste a cambiar}

Cuando se aborda la perspectiva de género en la comunicación, surge inmediatamente la necesidad de establecer unas categorías de análisis que permitan aproximarse a las diferentes realidades que se construyen en el discurso mediático. Una primera distinción se ha de perfilar necesariamente entre medios de comunicación, por un lado, y publicidad por otro. Los medios de comunicación englobarían los soportes tradicionales de prensa, radio y televisión, con el añadido de internet y toda la información que fluye en la misma. La actividad de los medios de comunicación, con la irrupción de Internet y la evolución vertiginosa que el consumo de medios está experimentando, está sometida a unos cambios sustanciales tanto en la función de los mismos, como en los distintos géneros y productos que generan.

La publicidad, por su parte, se construye en torno a imágenes (anuncios impresos, composiciones de imagen y texto para ser exhibidos en vallas publicitarias, 0 micro-relatos audiovisuales que se emiten fundamentalmente en televisión e 
internet) y constituye uno de los espacios comunicativos más influyentes, siendo una industria creativa muy activa y con un potencial extraordinario en la transmisión de roles. Cada vez más la publicidad comparte espacio con la información y el entretenimiento, borrando las fronteras entre una y otra, a lo que, sin duda, ha contribuido también el consumo de medios a través de la red. A su vez la publicidad desarrolla estrategias propias del discurso narrativo de ficción audiovisual, al incorporar videoclips y micro-relatos que estarían sujetos al mismo método de análisis.

Se estudia la influencia de los medios de comunicación y de la publicidad en la construcción de roles de género ya que son, simultáneamente, reproductores y creadores de los modelos normativos.

El discurso publicitario posee una gran fuerza de persuasión, que influye en la transmisión de valores y creencias; por ello es importante que la publicidad responda a los roles sociales que las mujeres han ido conquistando en las últimas décadas. La publicidad busca persuadir y seducir utilizando modelos simplificados, y la recurrencia al estereotipo funciona como una herramienta eficaz de transmisión de los valores tradicionales de la sociedad patriarcal. Si bien más recientemente la publicidad se esfuerza en muchos casos por presentar una imagen de las mujeres más cercana a sus roles profesionales y familiares, tal y como se ilustra en el estudio llevado a cabo en la última sección de este briefing, se observa con asombro cómo el cuerpo femenino y la sexualidad continúan marcando las campañas publicitarias. El objetivo de la publicidad es vender o promocionar un producto, y el sexo y la belleza, al igual que el poder, venden, por lo que resulta difícil disociar los estereotipos femeninos de los atributos que tradicionalmente han llevado implícitos asociados al placer, el deseo y la felicidad para un público cuya mirada masculina se ha socializado como normativa y se resiste a cambiar.

\subsection{Generación de espíritu crítico basado en años de investigación ${ }^{7}$}

La trayectoria del equipo pivota en torno a la idea fundamental de que la academia es un pilar esencial desde el que generar conocimiento y espíritu crítico para poder avanzar sosteniblemente hacia sociedades más justas.

\footnotetext{
${ }^{1}$ Estos son los libros publicados de forma conjunta por el equipo: Tratamiento de la violencia de género en la prensa vasca (Donostia-San Sebastián, Universidad de Deusto-Emakunde, 2005); Dirigir en femenino (Madrid, LID, 2009); Mujeres, formación y empleo: realidades y representaciones/ Emakumeak, prestakuntza eta enplegua: errelitateak eta irudipenak (Donostia-San Sebastián,
} 

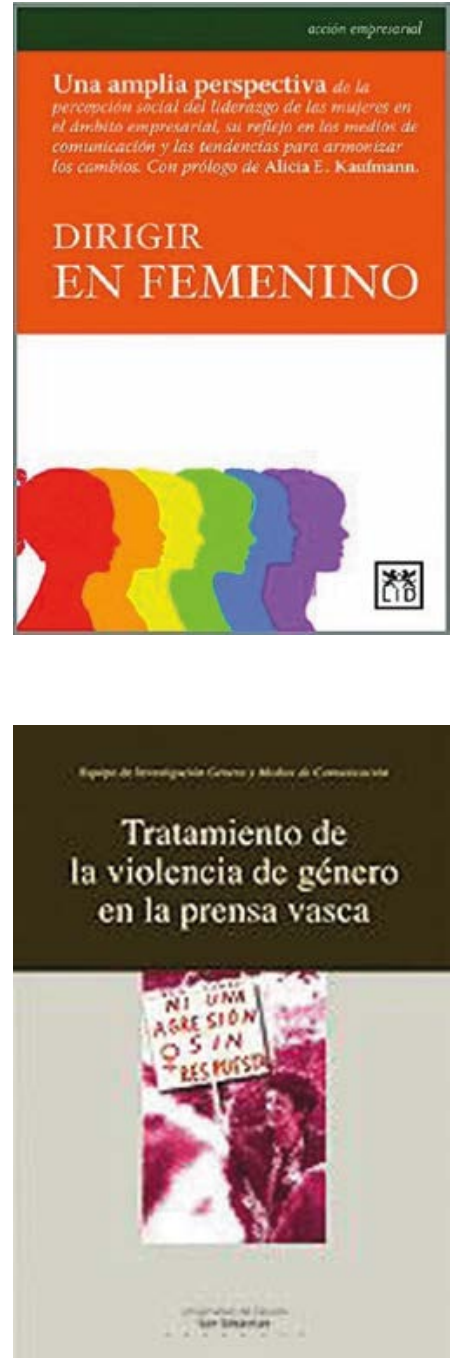

De un estudio realizado sobre el Tratamiento de la violencia de género en la prensa vasca se pueden extraer algunas nociones representativas de la importancia de incluir los estudios de género en relación a los medios de comunicación:

- A través de una serie de encuestas llevadas a cabo entre la población guipuzcoana, se advierte que el $70 \%$ conoce el problema de la violencia de género exclusivamente a través de los medios de comunicación. Nuestra imagen mental de ciertos acontecimientos se elabora en muchos casos a través de las informaciones que nos proporcionan la televisión, la prensa, la radio o Internet. Por ello, la forma en que los hombres y las mujeres aparecen representados es fundamental para ver cómo se van formando nuestras imágenes mentales en torno al género.

- El término "género» (estudios de género, violencia de género), que se defiende en el libro, va más allá de la mera diferenciación biológica y hace referencia a las construcciones culturales, a la creación social de ideas acerca de lo que es apropiado y conveniente para los hombres y para las mujeres. El concepto de género puede definirse como el conjunto de creencias, rasgos personales, actitudes, sentimientos, valores, conductas y actividades que diferencian a hombres y mujeres a través de un proceso de construcción social que tiene varias características.

GÉNERO: conjunto de creencias, rasgos personales, actitudes, sentimientos, valores, conductas y actividades que diferencian a hombres y mujeres a través de un proceso de construcción social.

Diputación Foral de Gipuzkoa, 2011); Representaciones de las mujeres políticas en la prensa (Bilbao, Publicaciones de la UD-Emakunde, 2012); Las mujeres deportistas en la prensa: los Juegos Olímpicos de Londres 2012 (Barcelona, UOC, 2015). 
En primer lugar, es un proceso histórico que se desarrolla a diferentes niveles: el estado, el mercado de trabajo, las escuelas, los medios de comunicación, la ley, la familia y a través de las relaciones interpersonales. En segundo lugar, este proceso supone la jerarquización de estos rasgos y actividades de tal modo que a los que se definen como masculinos se les atribuye mayor valor. Para referirse a la violencia ejercida por el hombre contra la mujer, los Institutos de la Mujer y las asociaciones de mujeres prefieren la denominación «violencia de género» a otras.

- Entre las recomendaciones que propone el libro para un tratamiento adecuado de la violencia de género en la prensa, se incluyen la de prestar atención a este problema de primera magnitud, ya que se basa en arraigadas desigualdades sociales y culturales subyacentes con información, seriedad y profesionalidad.

\section{Se debe apostar por la inclusión de reportajes y entrevistas desarrollados en profundidad, con presencia de expertas en el tema tratado y con la progresiva formación de los/las periodistas a quienes se adjudican este tipo de informaciones.}

Deben evitarse alusiones a situaciones románticas o amorosas. Tampoco conviene hablar de cada caso como un accidente o un suceso aislado. Por el contrario, se debe apostar por la inclusión de reportajes y entrevistas desarrollados en profundidad, con presencia de expertas en el tema tratado y con la progresiva formación de los/las periodistas a quienes se adjudican este tipo de informaciones. En ningún caso hay que incluir las opiniones de personas que conocían al agresor a quien descri-

ben con un buen chico o que contribuyan a denigrar a la víctima por su conducta, forma de vestir, etc.

En diciembre de 2007 todos los grupos del Parlamento Vasco lograron un acuerdo centrado en el análisis de la violencia de género en Euskadi y plantearon una batería de propuestas para avanzar en la igualdad de derechos entre hombres y mujeres, sensibilizar a la sociedad acerca del problema y mejorar la atención que las víctimas reciben de las administraciones ${ }^{2}$.

La noticia incluía la siguiente información: «El informe, que se aprobará el miércoles, atribuye a los medios de comunicación una importante

\footnotetext{
2 El País (2007). La ponencia sobre violencia de género logra el acuerdo de todos los grupos (título en cursiva). Vitoria 16 de Diciembre de 2007. Disponible en:http://elpais.com/diario/2007/12/16/ paisvasco/1197837599_850215.html https://www.google.es/webhp?sourceid=chrome-instant\&ion=1\&espv=2\&ie=UTF-8\#q=informe $\% 20$ del\%20parlamento\%20vasco\%20sobre\%20violencia\%20de\%20g\%C3\%A9nero\%202007
} 
responsabilidad en la prevención de la violencia de género y plantea que dispongan de un comité que supervise sus contenidos para evitar mensajes sexistas y sigan las recomendaciones del libro Tratamiento de la violencia de género en la prensa vasca, de la Universidad de Deusto, a la hora de informar» (El País, 16 de diciembre de 2007).

- La mejoría en el tratamiento de la violencia de género en los medios de comunicación es palpable y se van desterrando las informaciones sexistas o discriminatorias. Es este un ámbito en el que se pude llevar a cabo una labor de análisis crítico a través del estudio de informaciones pasadas y presentes para advertir los cambios que se han ido produciendo en los distintos medios hasta llegar a un tratamiento más justo.

\subsection{Diversos medios de comunicación y su impacto}

Dentro del conjunto de medios de comunicación se incluyen la televisión, la prensa escrita diaria y no diaria y las emisoras de radio, pero también, la publicidad, el cine, los discos y los vídeos y los medios basados en nuevas tecnologías (Internet: portales, periódicos electrónicos, blogs y páginas web).

Las principales funciones de los medios son las de

- difundir informaciones que permiten a la ciudadanía adquirir una percepción del mundo;

- contribuir a la cohesión social por el consenso que se establece en el intercambio de información, proporcionar compañía, entretenimiento y diversión;

- satisfacer demandas culturales y de conocimiento;

- legitimar el papel desempeñado socialmente por personas, organizaciones y movimientos sociales;

- legitimar los sistemas económico, político y cultural mediante la difusión de normas, valores, opiniones y actitudes sociales;

- fomentar el consumo y actuar como factores de desarrollo económico y contribuir al refuerzo de la identidad social ${ }^{3}$.

En esta identidad social la percepción de los roles de género y del papel que hombres y mujeres desempeñan en los cargos políticos, en las diversas categorías laborales y en los estamentos sociales, está fuertemente condicionada por los medios de comunicación y por la publicidad.

\footnotetext{
${ }^{3}$ Tal y como lo indica José Luis Sánchez Noriega (2006) Historia del cine. Teoría y géneros cinematográficos, fotografía y televisión (Madrid, Libros Singulares, pág. 620).
} 


\subsubsection{Televisión}

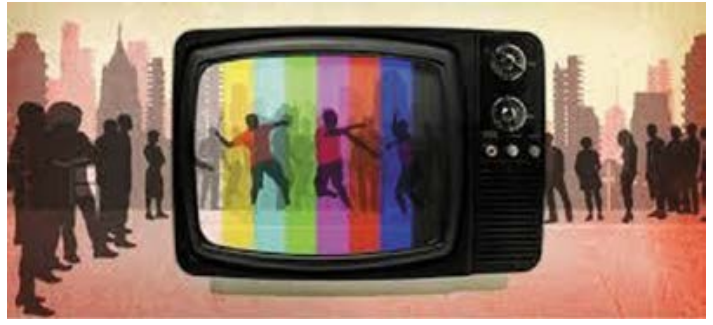

La televisión es el medio más popular en los hogares españoles. Durante el año 2015 el consumo de televisión fue de 237,7 minutos diarios por habitante (más de cuatro horas), mientras que esa cifra se reduce a 101, 5 minutos para la radio y 10,5 para la lectura de los diarios ${ }^{4}$. La televisión es un medio complejo que ofrece una programación muy variada, pero en lo referente al tratamiento de hombres y mujeres hay algunos datos ya constatados en diversos estudios especializados ${ }^{5}$.

1. En los informativos, hombres y mujeres aparecen representados de forma diferente. Los hombres aparecen como profesionales y son entrevistados en función del desempeño de su labor (políticos, deportistas, empresarios), mientras que las mujeres en la mayoría de los casos aparecen como voces anónimas sin valorar sus cualidades profesionales o sociales. En datos cuantitativos el porcentaje de mujeres entrevistadas es de $26,4 \%$ mientras que los hombres representan el 73,6\% (Benárdez, 169). Estos simples datos son suficientes para

¿Hay una mujer igualmente

capacitada que el hombre

entrevistado a quien no se

le da voz? ¿Está la mujer

entrevistada presentada por

su mérito o profesión? ¿Son

las figuras que representan

a las élites económicas,

políticas, deportivas, sociales

y culturales siempre o casi

siempre masculinas? que prestemos atención a los informativos y nos hagamos algunas sencillas preguntas: ¿Hay una mujer igualmente capacitada que el hombre entrevistado a quien no se le da voz? ¿Está la mujer entrevistada presentada por su mérito o profesión? ¿Son las figuras que representan a las élites económicas, políticas, deportivas, sociales y culturales siempre o casi siempre masculinas?

La publicidad televisiva reproduce los estereotipos de género de una manera tan acentuada que no trasluce los logros que las mujeres van alcanzando en todos

\footnotetext{
${ }^{4}$ Statista (2015) Promedio de tiempo diario destinado a consumir medios de comunicación en España en 2015, por tipo (en minutos). Disponible en: https://es.statista.com/estadisticas/491058/ consumo-diario-de-medios-de-comunicacion-en-espana-por-tipo/

${ }^{5}$ La información de este apartado se extrae principalmente del libro de Asunción Bernárdez titulado Propuestas para analizar la comunicación masiva con perspectiva de género (Madrid, Fundamentos, 2015).
} 
los ámbitos, sino que, por el contrario, las encasilla en los roles tradicionales de ama de casa y de madre. En un estudio realizado por el equipo ${ }^{6}$, se analizaron 275 anuncios distintos a partir de los mostrados en las principales cadenas que operaban de modo abierto.

El análisis arroja un panorama en el

Si la figura protagonista del anuncio aparece en calidad de experto, ¿es una figura masculina? ¿Aparece la mujer como destinataria principal de los anuncios orientados a la limpieza y al cuidado de los niños? ¿Hay una imagen femenina que debe responder en todos los casos a los cánones de belleza que la sociedad impone? que los hombres son los propietarios de los negocios, los que trabajan, los que estudian, los deportistas y los expertos en diversos campos. En los anuncios hay un personaje principal masculino que ejerce esas funciones y actividades laborales, mientras que en todos ellos también hay un personaje femenino que aparece como acompañante pasiva, como espectadora, como compañera o como persona beneficiada de las explicaciones del experto. Los resultados obtenidos en este estudio proyectan un mensaje para jóvenes y adolescentes en cuanto a sus expectativas de futuro en los ámbitos laborales y domésticos tremendamente desequilibrado en la representación. Algunas preguntas sencillas que deben trasladarse a este terreno al contemplar los anuncios televisivos son las siguientes: si la figura protagonista del anuncio aparece en calidad de experto, ies una figura masculina? ¿Aparecen las mujeres como destinatarias principales de los anuncios orientados a la limpieza y al cuidado de los niños? ¿Hay una imagen femenina que debe responder en todos los casos a los cánones de belleza que la sociedad impone?

2. En lo referente a los programas de entretenimiento tales como los reality shows y talk shows, se muestra la ilusión de romper las barreras entre lo público y lo privado. Frente a los programas «serios» que habitualmente son presentados por hombres, aquí predominan las mujeres como presentadoras, como participantes y como audiencia.

La pregunta fundamental debe ser la que plantea Asunción Bernárdez: «¿Qué tipo de representaciones de la feminidad ofrecen estos programas?» y responde: «La tendencia es que aparezcan modelos femeninos altamente estereotipados: la mujer ama de casa sacrificada y un poco simple; la mujer

\footnotetext{
${ }^{6}$ "Jóvenes y publicidad televisiva. Proyecciones del mundo laboral» Mujeres, formación y empleo: realidades y representaciones/Emakumeak, prestakuntza eta enplegua: errelitateak eta irudipenak (Donostia-San Sebastián, Diputación Foral de Gipuzkoa, 2011)
} 
Hay que observar con atención

estos espacios en los que

la presencia femenina es

mayor, pero en los que esa

representación femenina se

asocia a la distinción tradicional

entre mujer como "víctima»

o como "peligrosa», de modo

que las participantes son

sometidas a juicios morales

sexistas. ¿Qué trato reciben por

parte del público los hombres

y mujeres que participan

en estos programas? fatal que no hace feliz a ningún hombre; la madre abnegada y sin deseos propios; la adolescente descerebrada; la mujer del pueblo sin formación, pero con buenos sentimientos, etc.» (Bernárdez, 183). Hay que observar con atención estos espacios en los que la presencia femenina es mayor, pero en los que esa representación femenina se asocia a la distinción tradicional entre mujer como "víctima» o como "peligrosa», de modo que las participantes son sometidas a juicios morales sexistas. ¿Qué trato reciben por parte del público los hombres y mujeres que participan en estos programas?

3. Quedan otros muchos espacios que no se pueden analizar aquí, tales como las series de televisión, los programas deportivos, etc. En todos los campos se van produciendo avances y las mujeres van entrando en los espacios tradicionalmente masculinos y van adquiriendo voz en terrenos que antes les estaban vedados, pero todavía prevalece la desigualdad.

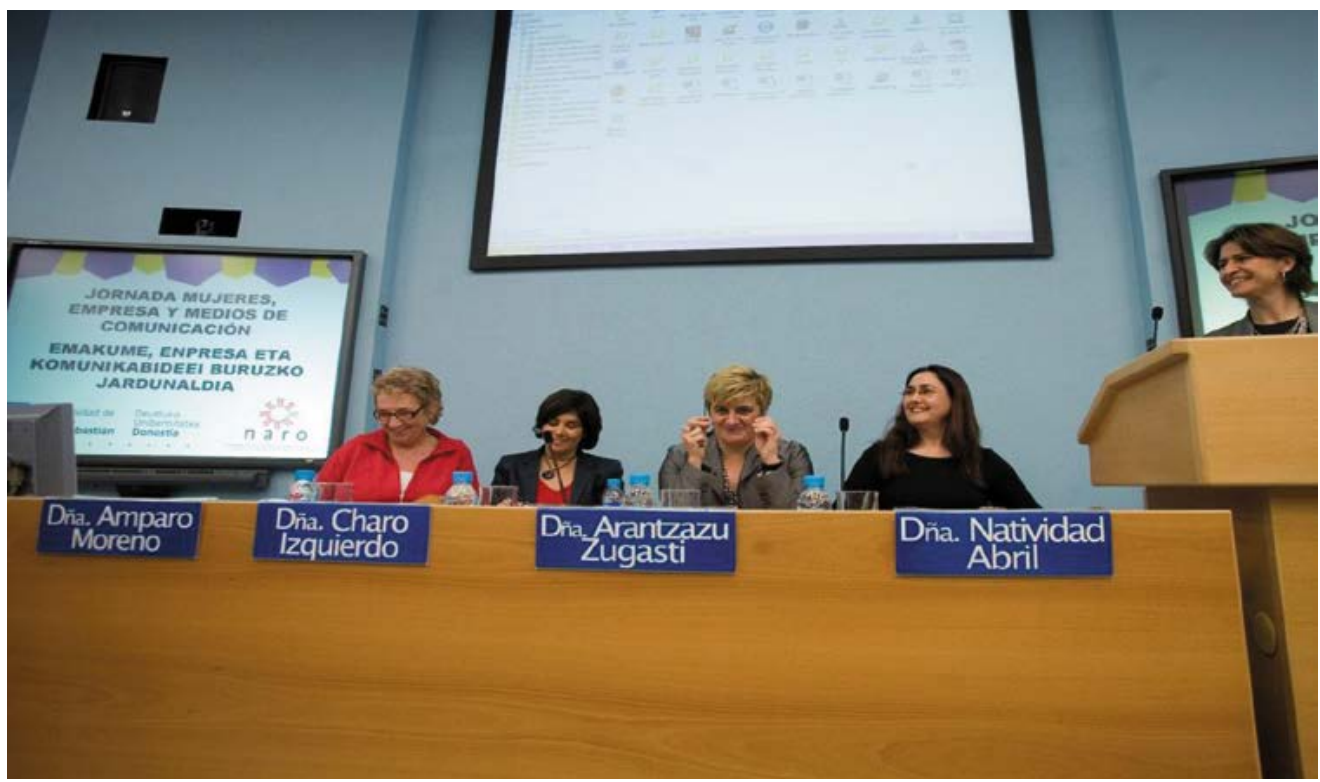

Jornada sobre Mujeres, empresa y medios de comunicación, UD-San Sebastián 


\subsubsection{Prensa}

La prensa ha sido el medio más analizado por el equipo. En todos los libros publicados se han llevado a cabo análisis cuantitativos, cualitativos y de contenido y se han estudiado todos los géneros: informaciones, entrevistas y reportajes, opinión e ilustraciones. Siguiendo el análisis crítico del discurso basado en la teoría de Teun A. van Dijk, entendemos que los discursos periodísticos no son objetivos porque siempre hay una ideología implícita en los mismos. Según las investigaciones desarrolladas por el equipo:

- Las mujeres ocupan menos espacio en las secciones de prestigio como la política, la economía, o las noticias internacionales. En muy pocos casos aparecen como expertas o representantes. En lo referente al tratamiento de hombres y mujeres en esferas de poder como la Política y la Economía resulta útil acudir al informe titulado España. Proyecto de Monitoreo Global de Medios 2010. Informe Nacional. En él se ofrecen cuantiosos datos acerca de la presencia de las mujeres en los medios de comunicación. En las 315 noticias monitoreadas, las mujeres representan solo el $23 \%$ de las personas que aparecen en la información. El informe señala que la presencia de hombres y mujeres en los distintos temas de la información presenta un orden inverso, es decir, donde existe una mayor presencia masculina es donde resulta más patente la ausencia femenina y a la inversa. Por ejemplo, mientras que el tema de la infancia y la juventud es el que registra mayor número de menciones femeninas, se sitúa en último lugar en cuanto a las masculinas. Otra muestra la tenemos en los ítems de presencia femenina que aparecen en último lugar: política y economía son áreas en las que, por el contrario, se produce el mayor porcentaje de apariciones masculinas. Las descripciones de mujeres como políticas alcanzan el $25 \%$ En cuanto a la función que desempeñan las mujeres y los hombres mencionados/as en las

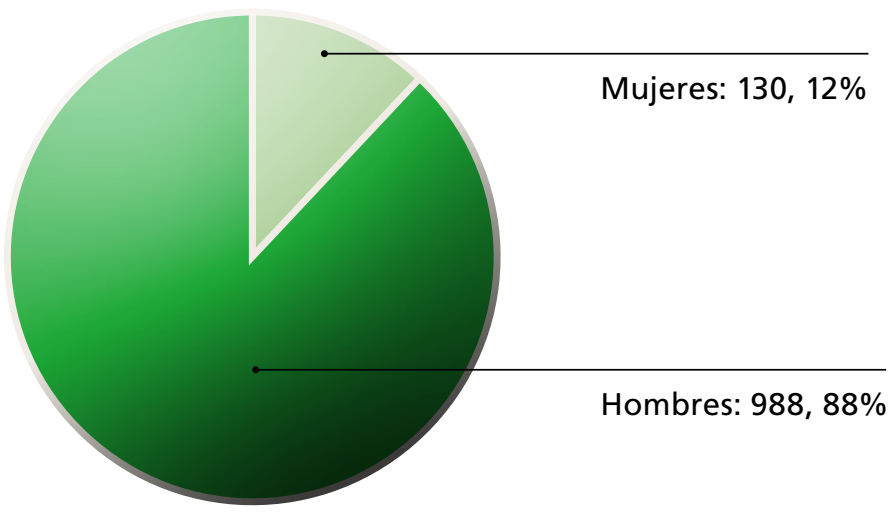




\section{La función de experto es la más}

frecuente en los hombres (91\%),

mientras que a las mujeres

sólo se les solicita su opinión

experta en el $9 \%$ de los casos noticias, la función de experto es la más frecuente en los hombres (91\%), mientras que a las mujeres sólo se les solicita su opinión experta en el $9 \%$ de los casos. Otro aspecto que contrasta enormemente es la situación de portavoz, en la que aparecen el $82 \%$ de los hombres y el $18 \%$ de las mujeres.

Es fundamental que las niñas y jóvenes tengan referentes en ámbitos de liderazgo y si el tratamiento que se hace de estas mujeres es denigrante, irrespetuoso o discriminatorio, el mensaje que se transmite desalienta a las jóvenes e impide el progreso social y económico.

Tomada en su conjunto toda la prensa analizada (El País, El Mundo, El Diario Vasco, Noticias de Gipuzkoa, Gara y Berria), la presencia es de un $12 \%$ de mujeres frente a un $88 \%$ de hombres en el ranking de personajes políticos que más aparecen en la prensa.

M.J. Korkostegi

- Cuando las mujeres aparecen como protagonistas o representantes de la política o de otros ámbitos de poder, en muchas ocasiones se hace referencia a su apariencia, a su vida privada y familiar, a su vestimenta o a otras cuestiones no ligadas directamente a su desempeño profesional. Hay una tendencia a referirse a las mujeres por su nombre de pila más que por su apellido, como se hace con los varones. Un ejemplo claro se recoge en el libro titulado Representaciones de las mujeres políticas en la prensa al analizar el trato diferente que se otorgó a Trinidad Jiménez y a Tomás Gómez en las Primarias de la Comunidad de Madrid, de octubre de 2010. Raúl del Pozo en la columna titulada «ZP; derrota en Callao» (El Mundo, 4 de octubre de 2010) comienza así: «La Trini, con su sonrisa Schweppes, no tomó Callao, que tiene nombre de derrota para ZP» (negritas y cursiva en el original). Más adelante hace referencia a su vestuario («chaqueta crema, pantalón vaquero, capullo en la mano»). El episodio de las primarias de Madrid adquirió una mayor intensidad en el tratamiento sexista de la candidata-y en su contestación y condena pública-a raíz del comentario de Alfonso Guerra el 6 de octubre, cuando afirmó: «Ganó el señor Tomás Gómez y los que 


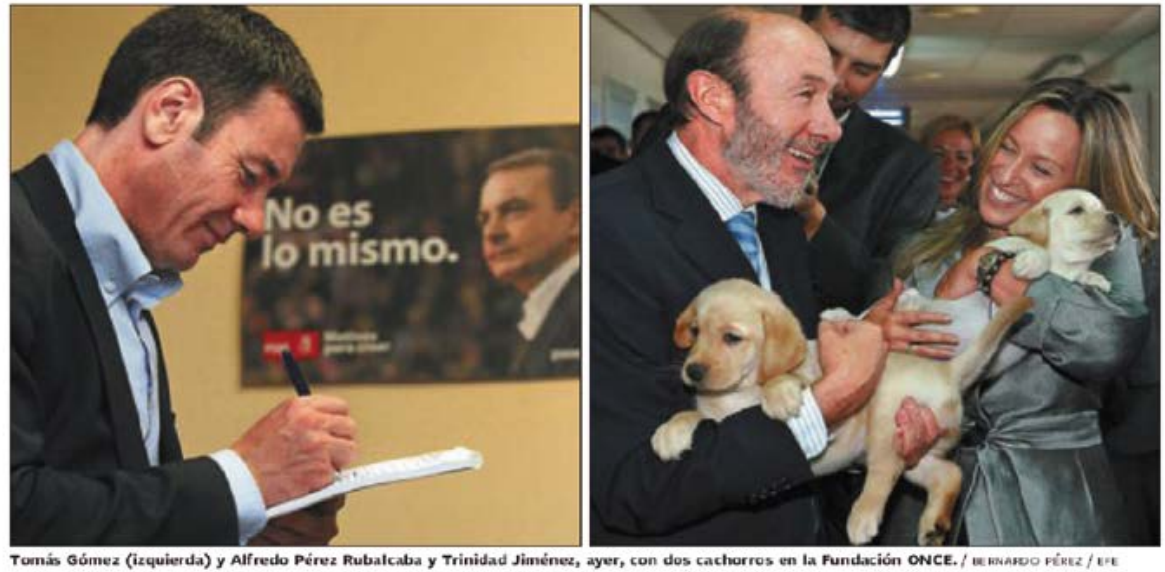

le apoyaban y no ganó la señorita Trini y los que la apoyaban, eso es evidente, y todo lo demás son interpretaciones para salir del paso».

- El Proyecto de Monitoreo Global de Medios (GMMP) es la investigación mundial más amplia y de mayor trayectoria que aborda el tema de género en los medios de comunicación. En el año 2015, a nivel nacional, se analizaron un total de 452 noticias repartidas en 65 de diarios impresos, 65 de radio, 88 de televisión, 61 de diarios digitales y 173 twits. Las mujeres comprenden solo el $28 \%$ del total de sujetos y fuentes en las noticias de prensa y los informativos de radio y televisión y el $33 \%$ en los diarios digitales y Twitter. Como sujetos de las noticias, las mujeres representan siempre menos del $30 \%$ del total: $28 \%$ en prensa, $26 \%$ en radio y $29 \%$ en televisión. En relación al área temática, las mujeres son una minoría en todas las informaciones excepto en las relacionadas con crimen

Las mujeres comprenden solo el $28 \%$ del total de sujetos y fuentes en las noticias de prensa y los informativos de radio y televisión y el 33\% en los diarios digitales y Twitter. Como sujetos de las noticias las mujeres representan siempre menos del $30 \%$ del total: $28 \%$ en prensa, $26 \%$ en radio y $29 \%$ en televisión. y violencia donde representan el $51 \%$ del total. En relación a las mujeres como fuentes de las informaciones, su mayor presencia es como fuentes de opinión popular $(43 \%)$, fuentes de experiencia personal (37\%) y sujetos de las noticias (35\%). El porcentaje más bajo lo tienen como expertas (9\%). Por tanto, cuando son los propios medios o productoras los que deben escoger a un experto en las noticias, excluyen a las mujeres como expertas y comentaristas.

- Es fácil ver que todos estos datos pueden dar lugar a una serie de análisis en las diversas etapas educativas para 
que niños y niñas y jóvenes sean conscientes de las representaciones de género que diariamente aparecen en los diversos medios y adquieran las destrezas y la capacidad crítica para saber entenderlas, cuestionarlas y ser capaces de elegir sus propias vías de información o, al menos, de no aceptar de modo inmediato informaciones con rasgos sexistas o discriminatorios.

\section{Designación por género. Forma en la que se designa al personaje político protagonista en el titular, según su género}

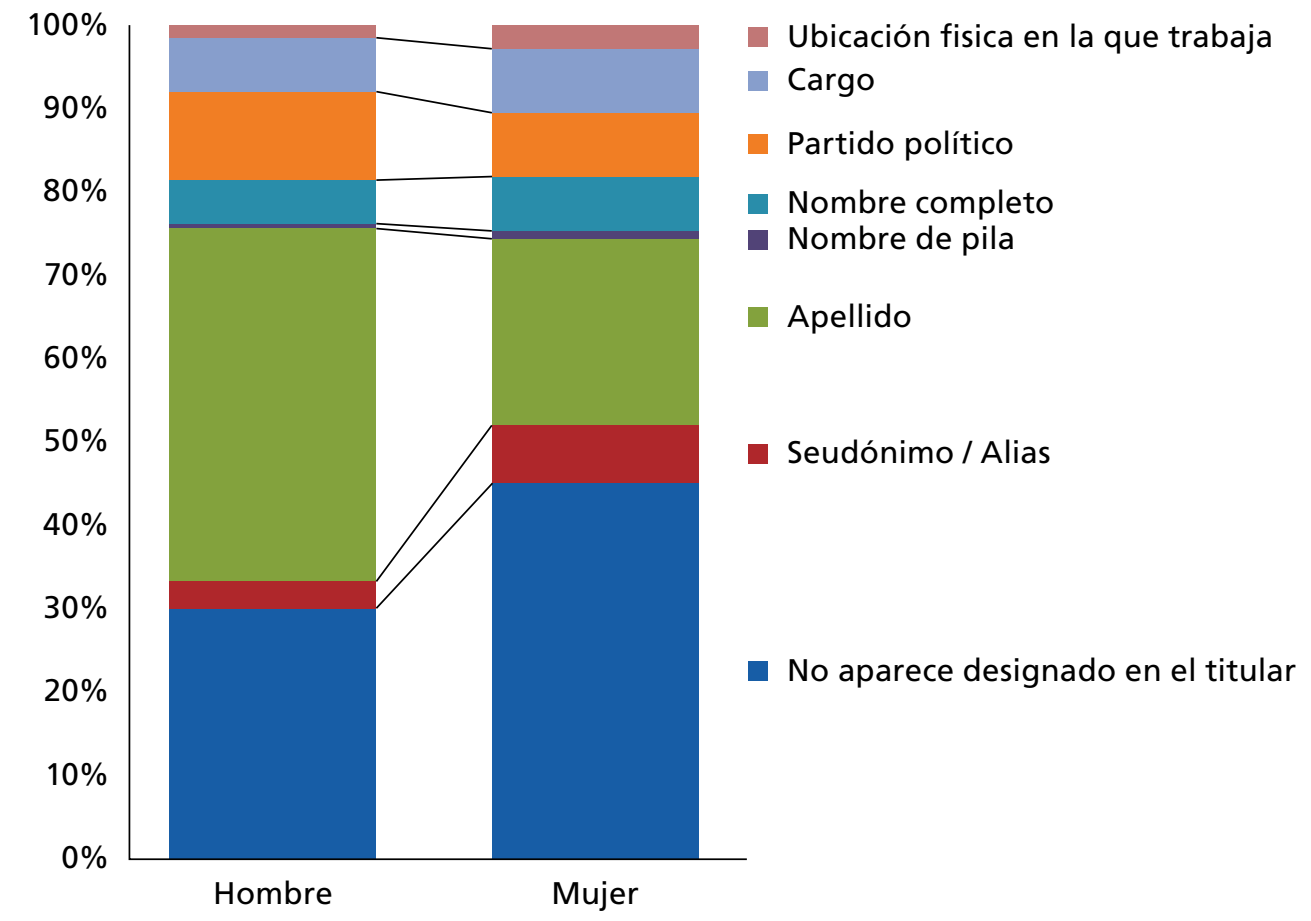

Fuente: Berasategi, Representación de las mujeres políticas en la prensa, (2010)

\subsubsection{Internet y las redes sociales}

Las Tecnologías de la Información y de la Comunicación (TIC) se han convertido en las principales transmisoras de información, conocimiento y entretenimiento. Como sucede en otros medios y canales de información, también aquí existe la llamada brecha de género, ya que la Unión Internacional de Telecomunicaciones (UIT) estima que hay cerca de 250 millones menos de mujeres que tienen acceso a las TIC que hombres en todo el mundo. Hay países en los que existe un equilibrio 
entre el acceso de hombres y mujeres a la red (como Islandia con 96,9\% para los hombres y $95,5 \%$ para las mujeres), y otros con una fuerte desigualdad (como India o Egipto). España se sitúa en un nivel intermedio con una media del $72,4 \%$ de hombres frente al 67,2\% de mujeres que acceden a la red (ver Bernárdez, 222).

Existe otro tipo de brecha digital de género, ya que las mujeres acceden principalmente como usuarias a la red, pero existe una gran desigualdad en cuanto a su participación como expertas en tecnología, ya que su presencia como programadoras y diseñadoras de programas y de páginas web está marcada por el dominio masculina de áreas en la educación, la investigación y el empleo relacionadas con las ingenierías y la tecnología.

Internet se ha convertido en

un lugar muy visible para

las luchas de género y así

como los ataques misóginos

son frecuentes, también las

denuncias y el desprecio

hacia quienes elaboran

este tipo de mensajes

adquieren una gran fuerza

La mayor preocupación hoy en día sobre los formatos y contenidos de la red y de las redes sociales reside en el hecho de que, al igual que el resto de los medios estudiados, se desarrollan sobre un modelo de representación patriarcal y se asientan en una serie de valores que en muchos casos son dañinos para las imágenes de las mujeres. Las nuevas tecnologías tienen la carga de arrastrar unos modelos patriarcales marcados por la discriminación, pero a su vez, el potencial de ser un mundo mucho más abierto y con un fuerte componente de participación que permite combatir la desigualdad. Remedios Zafra subraya la capacidad de resistencia que debe impulsarse para que la red no sea un simple lugar de intercambio económico y de conocimiento donde los estereotipos se perpetúan.

Existe otro tipo de brecha digital de género en cuanto a la participación de las mujeres como expertas en tecnología, programadoras y diseñadoras de programas y de páginas web en ámbitos relacionados con las ingenierías y la tecnología de dominio masculino en la educación, la investigación y el empleo.

La enseñanza para adolescentes y jóvenes debe estar basada, como apunta Asunción Bernárdez, en el uso de la red para generar nuevas preguntas y actividades creativas y no resignarnos a ser meras usuarias pasivas, fomentando la reflexión crítica y actuando frente a la desigualdad (Bernárdez, 231). Una de las preocupaciones actuales se relaciona con las redes sociales y la reproducción del sistema de violencia y de control que existe en la sociedad. 
Internet se ha convertido en un lugar muy visible para las luchas de género y así como los ataques misóginos son frecuentes, también las denuncias y el desprecio hacia quienes elaboran este tipo de mensajes adquieren una gran fuerza. La educación en este medio resulta fundamental y la capacidad de actuación es una de las fortalezas que favorecen la intervención para la construcción de identidades más igualitarias.

\subsubsection{Publicidad}

Los mensajes del lenguaje

publicitario descansan en activar

el deseo individual a través

de discursos que transmiten

valores incondicionalmente

aceptados por la colectividad,

tales como la seguridad, el amor, la belleza o el éxito social
Como se ha apuntado más arriba, la publicidad sigue siendo uno de los ámbitos en los que los roles de género inciden de manera más marcada. ¿Por qué persisten en la publicidad los estereotipos más que en cualquier otro ámbito? Los y las expertas atribuyen esta resistencia a lo que se denomina «estrategia de ahorro cognitivo» (Bernardez, 84), es decir, el estereotipo funciona como un modelo cultural normalizado en la representación de hombres y mujeres; en el caso del discurso publicitario, esta representación estereotipada de mujeres y hombres va comúnmente asociada a valores colectivos vinculados con la gratificación emocional inmediata, en la que confluye el deseo individual con el imaginario colectivo dominante. La publicidad no persigue representar la realidad tal y como es sino activar el deseo de los individuos y provocar reacciones emocionales que impulsen al consumo de un determinado producto, sea éste un automóvil, un seguro de vida, un electrodoméstico o un partido político. Los mensajes del lenguaje publicitario descansan, por tanto, en activar el deseo individual a través de discursos que transmiten valores incondicionalmente aceptados por la colectividad, tales como la seguridad, el amor, la belleza o el éxito social. Consecuentemente, constituye un instrumento poderosísimo de transmisión de valores y de conductas que se consume de forma acrítica y que penetra intensamente en el imaginario cultural. 
No es de extrañar, por tanto, que en los últimos años mucho del trabajo realizado sobre el tratamiento de género en los medios de comunicación se centre en el análisis y denuncia del discurso publicitario. En el análisis de publicidad y medios llevado a cabo por este grupo de investigación en 2014 para BEGIRA (Comisión asesora de publicidad no sexista) del Instituto Vasco de la Mujer - Emakunde?, se constató que la publicidad sigue acaparando muchos de los análisis de medios. Gobiernos nacionales, organismos internacionales como el Gender Monitoring Media Project (GMMP) que publica informes cada cinco años desde 1995, e instituciones supranacionales como la Unión Europea a través de resoluciones y recomendaciones del Parlamento Europeo y del Consejo de Europa, muestran su interés y preocupación por la persistencia con la que modelos tradicionales de género se instalan en el mundo publicitario y en la producción de los medios de comunicación, en especial de las televisiones, y se esfuerzan por establecer códigos de conducta para todos los países miembros. Se aboga por una autorregulación que vaya corrigiendo poco a poco los desajustes que existen entre una realidad cambiante y más igualitaria y una publicidad y unos medios que tercamente siguen reproduciendo estereotipos obsoletos y se resisten a incorporar nuevos modelos y nuevas voces. De ahí que se deposite la atención no solo en los productos que salen de la publicidad y los medios, sino en quiénes los crean y en la educación de un público crítico y con capacidad discriminadora.

A modo de ejemplo: un análisis de tres spots publicitarios

En el mundo de internet y en la publicidad televisiva, que es la que está más estudiada, junto a la repetición de estereotipos sexistas y la exacerbación del rol de las mujeres como consumidoras compulsivas, se contempla también la posibilidad de creación activa de nuevos modelos de mujeres más acordes a la realidad.

Se presentan a continuación tres ejemplos de anuncios publicitarios emitidos por TV que expresan de alguna manera las sensibilidades que conviven hoy en el mundo publicitario respecto de las representaciones de género. Por una parte persisten los estereotipos y una mayor sexualización si cabe del cuerpo femenino, sobre todo en productos asociados con la belleza y la atracción sexual; en segundo lugar se presenta un modelo de lo que se podría denominar "sexismo suave" y que resulta interesante en tanto en cuanto revela cierta perplejidad en la construcción de nuevos modelos femeninos, más empoderados pero atrapados en prejuicios antiguos; y en tercer lugar se presenta un modelo de publicidad no sexista en la que los roles de género son intercambiables.

\footnotetext{
7 María Pilar Rodríguez, María Jesús Pando, Esther Ferrer y Miren Berasategi: Meta-análisis sobre estudios de publicidad y comunicación, 2014. Revisión y compendio, con perspectiva de género, de los estudios y materiales disponibles (Vitoria-Gasteiz, Emakunde).
} 


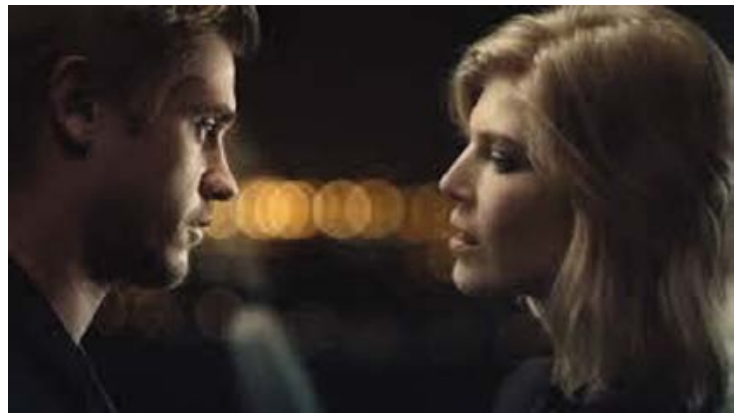

El primer ejemplo viene de un ámbito ya tradicional en el que la hipersexualización y los estereotipos persisten obstinadamente. Es el de la publicidad de cosméticos y perfumería. El anuncio es de Diesel Bad de la temporada otoño 2016. ${ }^{8}$. A través de un micro-relato esta fragancia masculina presenta dos modelos de conducta masculina y femenina marcadamente diferenciados y tristemente anclados en el maniqueísmo más rancio. Son estereotipos que se suponían superados hace años y que se enraízan en la tradición clásica del héroe errante cuya vida cargada de aventuras, peligros y experiencias trepidantes contrasta con la quietud y sumisión de una hipersexualizada figura femenina cuyo destino es aceptar el carácter rebelde de su amado y esperar sumisamente su retorno. El hombre promete amarla si ella acepta su condición (la de él) libre y nómada: frente a la acción masculina, la pasividad femenina; frente a la voz de él, el silencio de ella; frente a la asertividad y determinación, la sumisión y aceptación; frente a la libertad, dependencia, polarización que se representa también en la belleza sensual de la rubia modelo, frente a la apariencia atlética y vital del modelo moreno masculino, en una asociación semiótica de discursos, imágenes y colores absolutamente primaria.

El segundo ejemplo presenta un caso más problemático. Si bien la publicidad hoy en día se esfuerza en muchos casos por presentar una imagen de las mujeres más cercana a sus roles profesionales y familiares, se observa también cómo el cuerpo femenino y la sexualidad continúan marcando los mensajes publicitarios. En muchas ocasiones se trata de mensajes dirigidos a la población más joven, en los que los estereotipos tradicionales asociados a la feminidad se mezclan y se confunden con una especie de reivindicación que pretende asociarse a valores feministas y liberadores pero que acaba desembocando en modelos abiertamente sexistas. Tal es el caso del anuncio que la marca Desigual hizo público el Día de la Madre de 2014. En este spot comercial, una joven que está probándose un ajustado vestido de Desigual, introduce un almohadón para simular un embarazo mientras mira divertida y coqueta en el espejo su aspecto de embarazada. Seguidamente, tras chupar sensualmente un alfiler, agujerea con él un preservativo, al tiempo que el eslogan inicial de la campaña «Tú decides» se torna en «Feliz Día de la Madre». ¿Por qué este anuncio ha generado tanto ruido? Con toda seguridad está en el ánimo de las personas creadoras de este anuncio generar impacto y notoriedad, consustancial a la función primaria de la publicidad, pero sin duda la campaña, ya precedida por otros anuncios semejantes,

\footnotetext{
${ }^{8}$ https://www.youtube.com/watch?v=bX9EV3qZAe0

${ }^{9}$ https://www.youtube.com/watch?v=8D6OFJPvyRM
} 

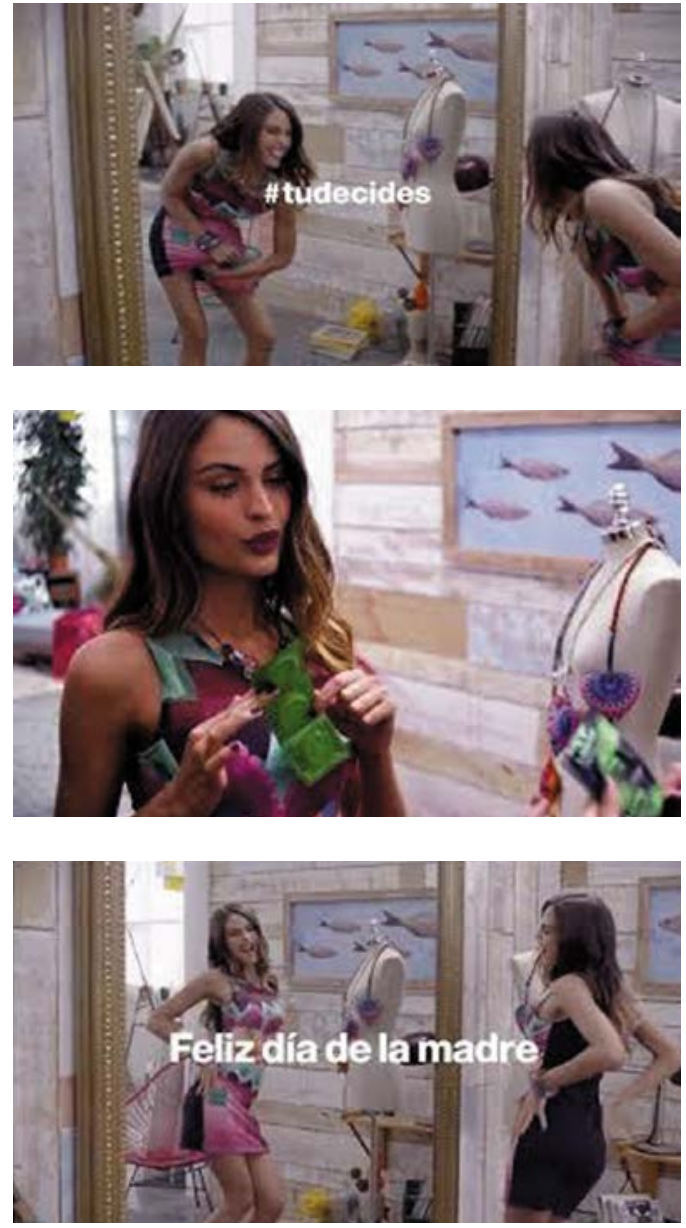

Lo que este anuncio representa sobre la evolución en las representaciones de género es la constatación de que, a pesar de que los modelos cambien, subyace a toda representación un imaginario del poder de la feminidad asociado al cuerpo, a la sexualidad y a la belleza perseguía también crear un relato original y fresco de mujer joven, sexy, divertida y coqueta que controla los hilos de su vida, de su cuerpo y de su destino: ella decide si quiere ser madre y en su acción persigue sin duda darle a la maternidad un toque jovial, sexy, divertido y sensual. Sin embargo, en el camino el relato se ha topado con un puñado de estereotipos que convierten un supuesto homenaje a la maternidad y a la capacidad de las mujeres para decidir en una expresión de frivolidad insultante para las madres, y de irresponsabilidad para las mujeres y hombres jóvenes que se quieren enfrentar a las relaciones sexuales en libertad e igualdad de condiciones. El anuncio refuerza el estereotipo de que el primer atributo de una mujer es ser atractiva y sexy, y que para ejercer su voluntad no escatima trucos y engaños, siempre relacionados con su sexualidad y su cuerpo. Así se confunde la libertad de elección con un comportamiento irresponsable, frívolo y tramposo que contribuye a fijar el gran cliché que tradicionalmente ha definido la naturaleza femenina como maliciosa y embaucadora, en cuyos engaños caen víctimas indefensas los hombres. En su afán de transgredir y provocar, el anuncio no solo no ofrece una imagen liberadora de las mujeres, sino que las cosifica aún más, vinculando la maternidad a un mero «look» y la libertad a un frívolo y tramposo guiño al sexo. Lo que este anuncio representa, en fin, sobre la evolución en las representaciones de género es la constatación de que, a pesar de que los modelos cambien, subyace a toda 

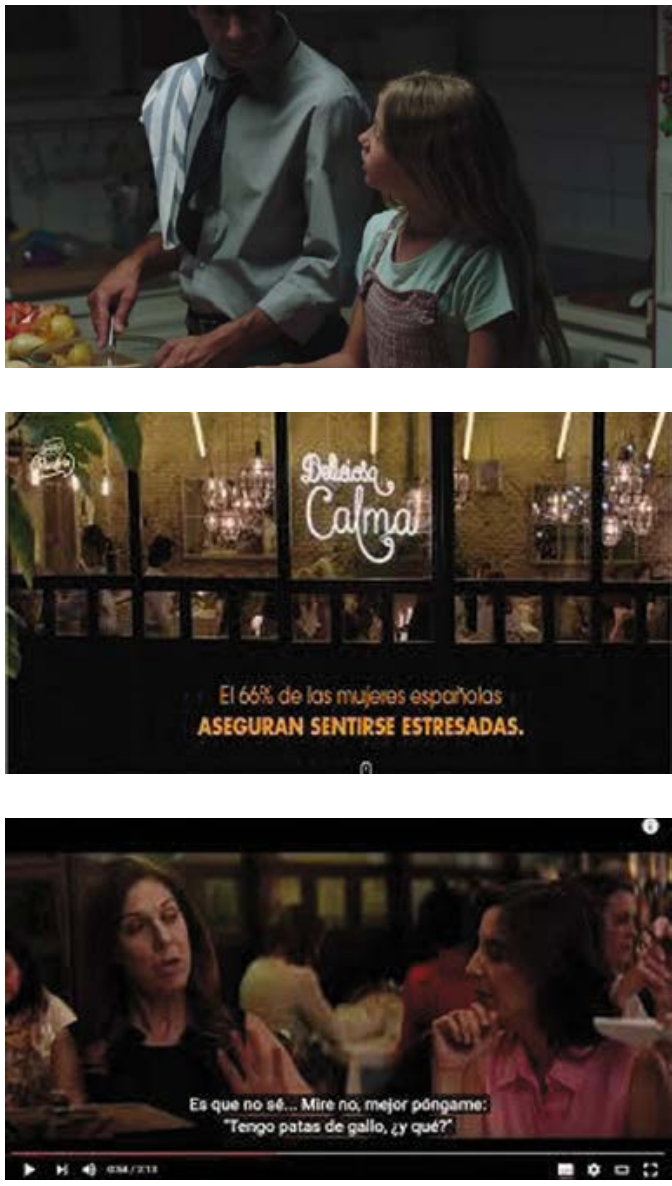

representación un imaginario del poder de la feminidad asociado al cuerpo, a la sexualidad y a la belleza.

Los cambios operados en la imagen publicitaria de las mujeres en los últimos años, que pasan de ser el objeto sumiso de la mirada masculina a un modelo de mujer más independiente, activa y asertiva en su identidad sexual son examinados por autoras como Rosalind Gill, quien cuestiona cómo opera ese supuesto empoderamiento en estas nuevas figuras dentro de lo que son las relaciones heteronormativas y cómo éstas configuran las relaciones de poder. De esta manera la actividad sexual de estas mujeres funciona como una especie de regulación que permite encajar la subjetividad femenina dentro de un marco postfeminista y neoliberal que, en el fondo, sigue reclamando que este nuevo modelo de mujer siga siendo no solo hermosa sino también sexy, sexualmente experimentada y siempre «dispuesta».

Frente a estos modelos, son los spots publicitarios relacionados con el consumo doméstico los que tal vez han avanzado más en la revisión de los roles tradicionalmente asignados a hombres y mujeres. $Y$ aquí va el tercer ejemplo. En estos casos ya no operan los valores asociados a la

Hacer el ejercicio crítico de intercambiar figuras masculinas

y femeninas en las narrativas

publicitarias facilita el

diagnóstico sobre el nivel de sexismo de un spot publicitario. belleza, el éxito y el atractivo sexual, sino aquellos relacionados con la seguridad, la felicidad y la vida familiar. Son ejemplos como el de "Salvemos las cenas» de Ikea $2016^{10}$ en el que el ámbito familiar de las cenas diarias se convierte en un espacio de diálogo, igualdad y tolerancia; o el ya famoso de Campofrío 2016 «Deliciosa calma»"

\footnotetext{
${ }^{10} \mathrm{https}: / /$ www.youtube.com/watch?v=-ER2jqVE6jQ

11 https://www.youtube.com/watch?v=aZSSiYvgxsU
} 
๑) Yang Liu Design / TASCHEN

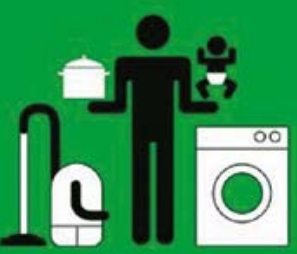

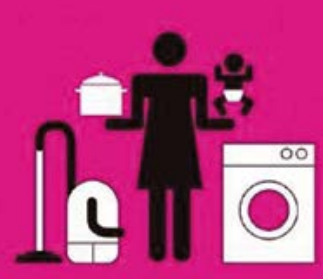

en el que mujeres de carne $y$ hueso, reales y exponentes de las clases medias trabajadoras rechazan colectivamente las tiranías de los estereotipos impuestos y reivindican el derecho a envejecer, a estar gordas o a ser imperfectas.

En resumen, el consumo crítico de la publicidad $-\mathrm{y}$, por tanto, el rechazo a discursos que sistemáticamente denigran o desvirtúan a las mujeres, que las hipersexualizan o las despojan de autoridad- es fundamental para que progresivamente las industrias publicitarias construyan modelos de masculinidad y feminidad más acordes con los roles sociales que ambos desarrollan en sociedades modernas y con los objetivos de igualdad que en última instancia se persigue conseguir. En el caso de la publicidad dirigida a público infantil y adolescente este principio se hace aún más imprescindible, por cuanto contribuye a construir imaginarios colectivos de fácil asimilación y a modelar pautas de conducta. Hacer el ejercicio crítico de intercambiar figuras masculinas y femeninas en las narrativas publicitarias facilita el diagnóstico sobre el nivel de sexismo de un spot publicitario.

\section{RECOMENDACIONES}

Educar a niños, niñas y jóvenes en los formatos principales de los medios de comunicación en conexión directa con los principios básicos de los estudios de género.

Desarrollar las competencias para el análisis y el espíritu crítico que permitan cuestionar la transmisión de los estereotipos de género en los medios de comunicación.

Analizar las imágenes, las informaciones y las noticias y rechazar cualquier representación de las mujeres que obstaculice o impida su desarrollo social y profesional.

Trabajar en el desarrollo de una conciencia crítica ciudadana que contribuya activamente a una representación más justa y más igualitaria de las mujeres mediante la identificación y la protesta de modelos estereotipados y discriminatorios.

Trabajar en la inclusión de modelos de mujeres que reflejen la diversidad de sus contribuciones en el desempeño profesional evitando la victimización y la reproducción de estereotipos con el fin de contribuir a una sociedad más justa. 


\section{Referencias}

Bernárdez, Asunción (2015). Mujeres en medios. Propuestas para analizar la comunicación masiva con perspectiva de género. Madrid, Fundamentos

Equipo de investigación Género y Medios de Comunicación (2006). Tratamiento de la violencia de género en la prensa vasca. San Sebastián, Universidad de Deusto

Equipo de investigación Género y Medios de Comunicación (2011). Mujeres, formación y empleo: realidades y representaciones / Emakumeak, prestakuntza eta enplegua: errelitateak eta irudipenak. Donostia, Diputación Foral de Gipuzkoa.

Gill, Rosalind (2007). Gender and the Media. London, Polity Press

Korkostegi, Pando, Rodríguez, Sanz, eds. (2009). Dirigir en femenino. Madrid, LID

López Díez, Pilar (2004). «La mujer, las mujeres y el sujeto del feminismo en los medios de comunicación» en Manual de información en género. Pilar López Díez (ed.) Madrid: IORTV (RTVE) e Instituto de la Mujer

Rodríguez, Maria Pilar, ed. (2012). Representaciones de las mujeres políticas en la prensa. Bilbao, Publicaciones de la Universidad de Deusto

Rodríguez, María Pilar; Pando-Canteli, María Jesús; Ferrer, Esther y Berasategi, Miren (2014). Meta-análisis sobre estudios de publicidad y comunicación, 2014. Revisión y compendio, con perspectiva de género, de los estudios y materiales disponibles. Vitoria-Gasteiz, Emakunde

Sánchez Noriega, José Luis (2006). Historia del cine. Teoría y géneros cinematográficos, fotografía y televisión. Madrid, Libros Singulares

Sanz, Begoña, ed. (2015). Las mujeres deportistas en la prensa: los Juegos Olímpicos de Londres 2012. Barcelona, UOC 


\section{Notas biográficas}

\section{María Pilar Rodríguez}

María Pilar Rodríguez es profesora titular en el Departamento de Comunicación de la Universidad de Deusto. Es doctora por la Universidad de Harvard (Cambridge, EEUU). Hasta 2002 fue profesora en la Universidad de Columbia (Nueva York, EEUU). Ha publicado extensamente sobre literatura, cine, cultura y estudios de género. Es la Investigadora Principal del equipo Comunicación, reconocido por el Gobierno Vasco. Forma parte del consejo editorial y participa habitualmente en evaluaciones de revistas académicas tales como Bulletin of Hispanic Studies, Hispanic Review o European Visual Cultures. Imparte regularmente cursos en universidades norteamericanas. Tiene reconocidos tres sexenios de investigación por la CNEAI y en 2015 obtuvo la Cátedra Koldo Mitxelena por parte del Gobierno Vasco.

\section{María J. Pando Canteli}

Es profesora titular del departamento de Lenguas Modernas y Estudios Vascos de la Universidad de Deusto, donde imparte clases de Estudios de Género, literatura contemporánea en inglés y de estudios europeos, tanto a nivel de grado como de máster y doctorado. Es doctora en Lengua y Literatura y ha enseñado también en la Universidad del País Vasco y en Santa Clara University (EEUU). Ha sido becaria postdoctoral Fulbright en la Universidad de Stanford (EEUU) entre 2008-2009 y "fellow» de la Folger Shakespeare Library (EEUU). Su investigación tiene como eje central los estudios de género, que trabaja por una parte en las relaciones literarias y culturales europeas en los siglos XVI y XVII y por otra en los estudios de comunicación. Ha publicado extensamente en los campos de Género y Comunicación y en el ámbito de los estudios culturales de la temprana modernidad.

\section{Miren Berasategi}

Miren Berasategi es licenciada en Humanidades: Comunicación (Deusto, 2004), Máster en Sociedad de la Información y el Conocimiento (UOC, 2008) y Experto Universitario en Métodos Avanzados de Estadística Aplicada (UNED, 2011) y Técnicas de Estadística Multivariante (UNED, 2011). Actualmente es profesora contratada en la Universidad de Deusto, donde imparte docencia en el campus de Donostia. Su actividad docente se concentra en el Grado en Comunicación, donde imparte las siguientes asignaturas: Proyectos para la Web y Messages for the Web. Pertenece al equipo de investigación de Comunicación reconocido por el Gobierno Vasco y actualmente trabaja en su tesis doctoral acerca de la enseñanza universitaria del periodismo de datos. 



\section{Do social media generate gender stereotypes? A critical reflection for educators}

María Pilar Rodríguez, María J. Pando-Canteli y Miren Berasategi

1. Introduction: the power of media discourse in the construction of gender identities ......................... 40

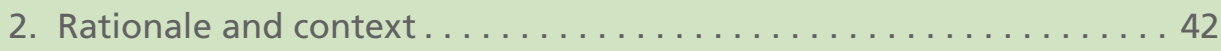

2.1. Why is it important to analyse the media from the gender per-

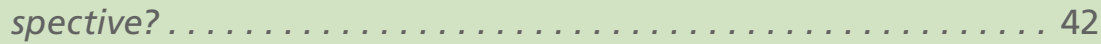

2.2. Who is the target audience of this briefing? ........... 43

3. Study Purpose: Media, Advertising and Gender ........... 45

3.1. Generating critical thinking based on years of research...... 46

3.2. Different media and their impact................. 48

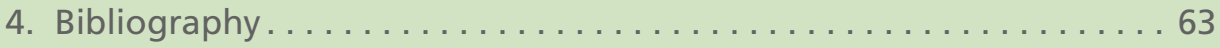

5. Biographical notes........................... 64 



\title{
Do social media generate gender stereotypes? A critical reflection for educators
}

\author{
María Pilar Rodríguez, María J. Pando-Canteli y Miren Berasategi
}

doi: http://dx.doi.org/10.18543/dsib-1(2016)-pp119-144.pdf

\section{Abstract}

This briefing highlights the importance of media in the formation and transmission of gender identities. Examples are given from the press, from TV, from advertising and from the Internet to illustrate clearly and directly the presence of sexist stereotypes and their influence on the construction of our images of women and men. The briefing seeks to encourage critical thinking in analysing the power of media discourses in the construction of easily consumable symbolic universes in which the feminine and the masculine occupy very different hierarchical levels.

\section{Keywords:}

media, gender, stereotypes, education, equality.

\section{Resumen}

Este briefing expone la importancia de los medios de comunicación en la construcción de las identidades de género. Se muestran ejemplos de la prensa, de la televisión, de la publicidad y de Internet para ilustrar de modo claro y directo la presencia de los estereotipos sexistas y su influencia en la construcción de nuestras imágenes sobre las mujeres y los hombres. Promueve el desarrollo del espíritu crítico para analizar el poder que tienen los discursos mediáticos en la construcción de universos simbólicos de muy fácil consumo, en los que lo femenino y lo masculino ocupan jerarquías muy distintas.

\section{Palabras clave:}

medios de comunicación, género, estereotipos, educación, igualdad. 


\section{Introduction: the power of media discourse in the construction of gender identities}

This briefing considers the importance of the media in the construction of gender identities. It is the outcome of lengthy reflection on the power of the media and its capacity to produce, perpetuate or amend social conduct guidelines and the collective imagination.

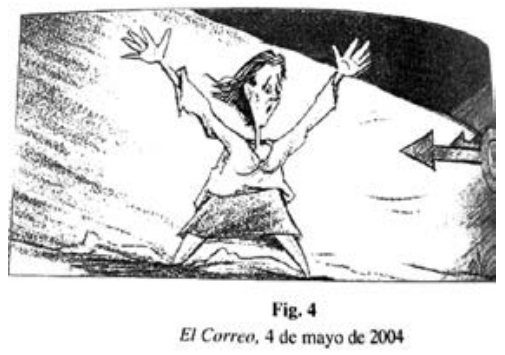

It seeks to contribute to awareness-raising among society in general and among educators as a whole in particular about the power that media discourse has in the construction of easily consumable symbolic universes, where female and male occupy very different hierarchies.

Therefore, this paper is mainly aimed at educational institutions that have to face the daily task of contributing to the development of core competencies in children and adolescents, particularly regarding their permanent exposure to media consumption where there are no filters and for which neither adults nor minors are prepared.

In order to openly reflect

and provide critical analysis

instruments, this contribution

particularly seeks to raise

awareness among society in

general and among educators

in particular, both in the

school and in the family

Educators in general are particularly relevant as they embrace the responsibility of instilling the values and sufficient critical judgement in the upcoming generations to create free and equal individuals. Only in this way, from an informed and critical citizenry, will it be possible to overcome intolerances and prejudices, and for those young people to be responsible consumers, with a real capacity of choice and ability to discern.

Furthermore, pointers are provided for communications students and professionals, but who are not trained in gender studies, who are called on to generate new critical media products using some of the existing models.

The aim of fostering tolerant, critical and free citizens underpins the principles of the educational systems of advanced and democratic countries. This briefing seeks to be a space for reflection on the need for early literacy in media consumption, as a more fundamental aspect of the holistic education of a citizen in the $21^{\text {st }}$ century. 
Media analysis from the gender perspective can be addressed from different angles (production, depiction, target audience). This briefing focuses on what has been called representation: how men and women are depicted in the different information genres and media outlets and which strategies underpin that representation.

\section{Representation}

How men and women are

depicted in the different

reporting genres and media

outlets and which strategies

underpin that representation

The media both simultaneously depict and create the female and male models, in other words, what is socially and culturally deemed adequate in terms of being a woman and of being a man. In fundamental aspects of social life, people in general have no direct knowledge based on their experience of fundamental issues linked to gender constructions and their mental image is
we today have more data than ever and shaped through the media. Even though we today have more data than ever and access to information is direct and immediate, real knowledge requires learning about the way in which the media prepare their reporting and about the interests that often underpin the news, documentaries and op-ed articles.

Therefore, the aim is to spotlight relevant aspects of the different research that may further understanding, with specific examples, of how those depictions are constructed in the different media outlets and, by critically analysing the discourse, identify the mechanisms that contribute to producing those messages. We therefore analyse television, press, advertising and Internet, and use representative examples to reveal the ways in which the press, television and advertising construct the news, reports and entertainment programmes according to certain stereotypes that accentuate inequality.

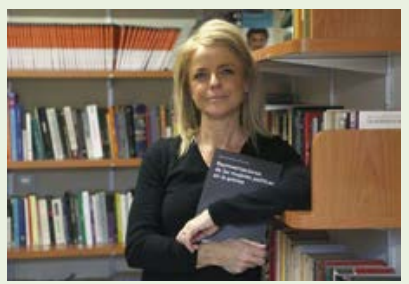

This briefing sets out the results of studies conducted by the Gender and Media research team at the Communications Department of the Social Sciences and Humanities Faculty at Deusto University-San Sebastián, headed by María Pilar Rodríguez and comprising Miren Berasategi, María Jesús Korkostegi, María Jesús Pando, Ana Isabel Recalde and Begoña Sanz. The team has worked with members of other DEUSTO faculties to reinforce its interdisciplinary nature. 


\section{Rationale and context}

Interdisciplinary research on women's and gender studies must necessarily be based on the basic premise that social progress is not only achieved from the implementation of new corrective policies or new citizen initiatives, but rather from the capacity to generate new theoretical frameworks that allow social change to be advanced. Given this conviction, a well-structured integral model of social change in the fight for equality needs to be based on:

- Research that critically reviews existing models and explores new theoretical frameworks.

- Transfer of that knowledge through curricular models that promote critical thinking.

- And finally, the application of that knowledge in society by means of specific actions that contribute to eradicate those inequalities.

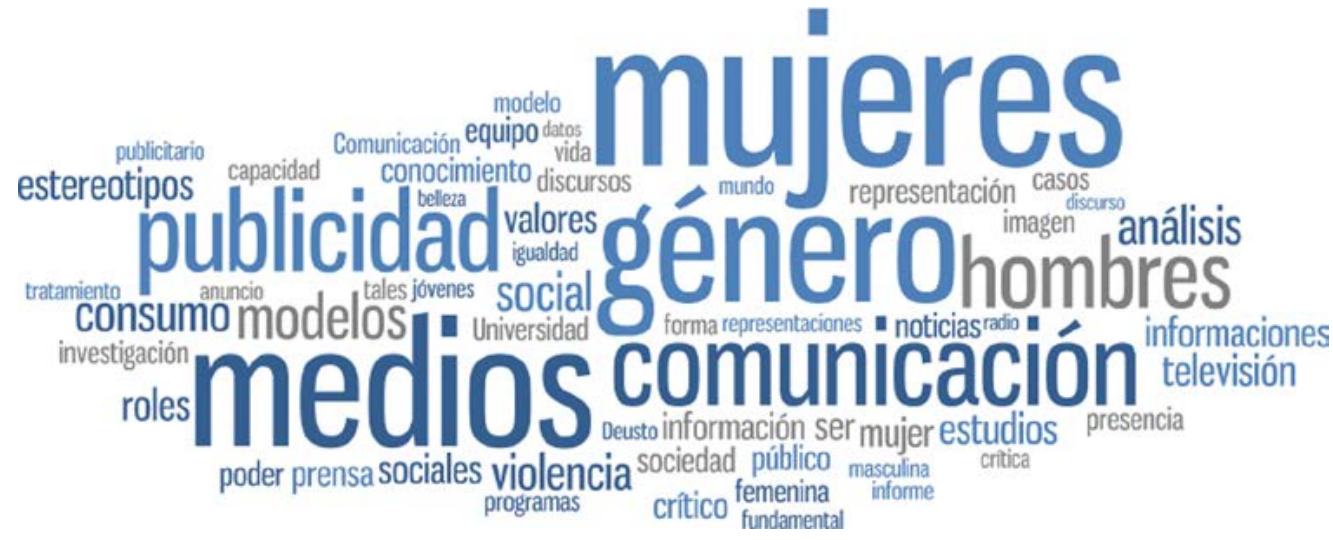

\subsection{Why is it important to analyse the media from the gender perspective?}

The power of the media as not merely transmitters but active producers of reality is widely documented. They are industries and institutions that act in a globalised market, but which daily penetrate our homes and shape how cultural, economic, social and political spheres are depicted. The media play a key role in the construction of the image of the world espoused in the collective imagination. Current affairs, the value of a news item and its prioritisation, the film industry, the advertising of consumer goods and its ubiquitous presence in the daily lives of people, are all constructing our daily reality and structuring our scale of values and establishing role models. 
Current affairs, the value

of the news item and

its hierarchisation in the

journalistic routine, the film

industry, the advertising

of consumer goods and its

ubiquitous presence in the

daily lives of people, are

all constructing our daily

reality and structuring

our scale of values and

establishing role models
It is, therefore, fundamental to carefully study how those discourses are constructed, which collective life models they transmit and how they contribute to reinforce inequalities or, on the contrary, to foster models of equality and of coexistence. Finally, it should be noted that we are taught to understand and produce written discourses, to come to grips with encoding and decoding a written text, but not to critically deal with a complex audiovisual message, whether it is an item in the news, a television reality show or an advertising video clip.

\subsection{Who is the target audience of this briefing?}

The overwhelming presence

of the media in the daily

lives of people makes a

critical understanding of the production and consumption

of information, entertainment and advertising a pressing educational priority
The overwhelming presence of the media in our daily life makes a critical understanding of the production and consumption of information, entertainment and advertising a pressing educational priority. However, educational systems still not have included it in their curricular developments. Even though literacy and textual understanding skills are a priority in secondary and primary education, the same does not occur with media and audiovisual «literacy», despite children and young people being exposed to digital and audiovisual discourses with much greater frequency and intensity than to merely textual written communication.

On the one hand, there is a lack of awareness about how to address entertainment products and media consumption and, on the other hand, educational tools in schools and in families to critically get to grips with discourses that frequently depict inequalities of every type and exalt violence beyond tolerable levels. 
In a context of globalised consumption of audiovisual products, training that allows us to address this reality with a critical and comprehensive approach is required. It is, therefore, particularly important that educators are involved in the task.

Critical thinking is created by means of a process that consists, first of all, of revealing the techniques and procedures used by the different media to prepare their reporting and arguments and, secondly, of applying the necessary interpretation techniques to understand the intent underlying the messages. The outcome is a citizenry capable of critical thought and that is the first step for social awareness that, ultimately, can lead to actions and projects to achieve a fairer and more equalitarian society.

The reflection proposed here helps to eliminate undesired effects in media consumption, such as the narcotic effect that occurs with repeated news items in cases such as the deaths of women victims of gender-based violence. It is particularly important that educators become involved in the task of training children and adolescents in the acquisition of the critical skills that enable them to perceive and question racist, sexist and discriminatory discourses in general. In a context of globalised consumption of audiovisual products, there is the pressing need for training that allows this reality to be addressed with a constructive and critical spirit and a sense of citizenship.

Anyone who acquires such critical awareness is not only better prepared to be involved in personal commitment actions aimed at ensuring human rights and gender equality are not disregarded or lost causes, but also for that person to more robustly exercise his or her civil rights and make a more critical contribution to a fairer society. 


\section{Study Purpose: Media, Advertising and Gender}

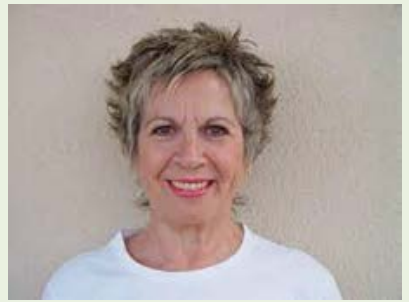

Looking, decoding, understanding, interpreting from the position of women's reality; preparing, constructing, theorising, writing, painting, photographing from the position of the reality seen by women seeking to change their situation in the patriarchy, is to contemplate gender perspective.

Pilar López Díez. La mujer, las mujeres y el sujeto del feminismo en los medios de comunicación.

The influence of the media and of advertising in constructing gender roles is studied, as they simultaneously depict and create the standard models, in other words, what is socially and culturally considered to be appropriate or suitable. Stereotypes affect society overall, women and men alike, as they transmit a rather unbalanced, unfair and disproportionate image on many occasions. They likewise have the capacity to foster pioneering images and question stereotypes and contribute to a more equal society. Yet that does not always occur, as both the media and advertising are frequently resistant to changes in roles and opt for easily consumable models.

\section{The male gaze has been}

\section{mainstreamed as the norm}

and is resistant to change
When the gender perspective in communication is addressed, a need immediately emerges to establish analysis categories for the different realities constructed in the media discourse to be approached. An initial distinction

needs to be established between the media, on the one hand, and advertising, on the other. The media encompasses the traditional press, radio and television outlets, with the addition of Internet and all the information that flows in it. The activity of the media, with the arrival of Internet and the fast development that media consumption is undergoing, is subject to substantial changes both in how the media function and in the different genres and products that they generate.

Advertising, in turn, is constructed around images (printed adverts, text and image compositions to be exhibited on advertising hoardings, or audiovisual micro-tales that are fundamentally broadcast on television and online). It is one of the most influential communication spaces, as it is a very active creative industry and with extraordinary potential for role transmission. Advertising is increasingly 
sharing space with information and entertainment, with the borders between both becoming blurred, to which media consumption online has, undoubtedly, contributed as well. Advertising in turn develops its own strategies of the audiovisual fiction narrative discourse, by incorporating video clips and micro-tales that would be subject to the same analysis method.

The influence of the media and adversiting in the construction of gender roles is studied as they simultaneously reproduce and create the norms.

Advertising discourse is highly persuasive, which influences the transmission of values and beliefs. It is therefore important for advertising to respond to the social roles that women have managed to conquer in recent decades. Advertising seeks to persuade and seduce by using simplified models, and resorting to the stereotype functions as an effective tool for transmitting the traditional values of the patriarchal society. Even though advertising has recently strived in many cases to present an image of women closer to their family and professional roles, as can be seen in the study conducted in the last section, it is astonishing to see how the female body and sexuality continue to define the advertising campaigns. The aim of advertising is to sell or promote a product, and sex and beauty, in the same way as power, sell. It is therefore difficult to dissociate female stereotypes from the attributes that have traditionally been implicitly associated to pleasure, desire and happiness for an audience whose male gaze has been mainstreamed as the norm and is reluctant to change.

\subsection{Generating critical thinking based on years of research}

The experience of the team revolves around the fundamental idea that academia is an essential pillar from which knowledge and critical thinking are generated in order to be able to sustainably advance towards equality.

From a study conducted on The Treatment of Gender-Based Violence in the Basque Press, some notions can be extracted that show the importance of media-related gender studies being included:

\footnotetext{
1 These are the books jointly published by the team: Tratamiento de la violencia de género en la prensa vasca (Donostia-San Sebastián, Deusto University-Emakunde, 2005); Dirigir en femenino (Madrid, LID, 2009); Mujeres, formación y empleo: realidades y representaciones/Emakumeak, prestakuntza eta enplegua: errelitateak eta irudipenak (Donostia-San Sebastián, Gipuzkoa Provincial Council, 2011); Representaciones de las mujeres políticas en la prensa (Bilbao, Publications of the DU-Emakunde, 2012); Las mujeres deportistas en la prensa: los Juegos Olímpicos de Londres 2012 (Barcelona, UOC, 2015).
} 

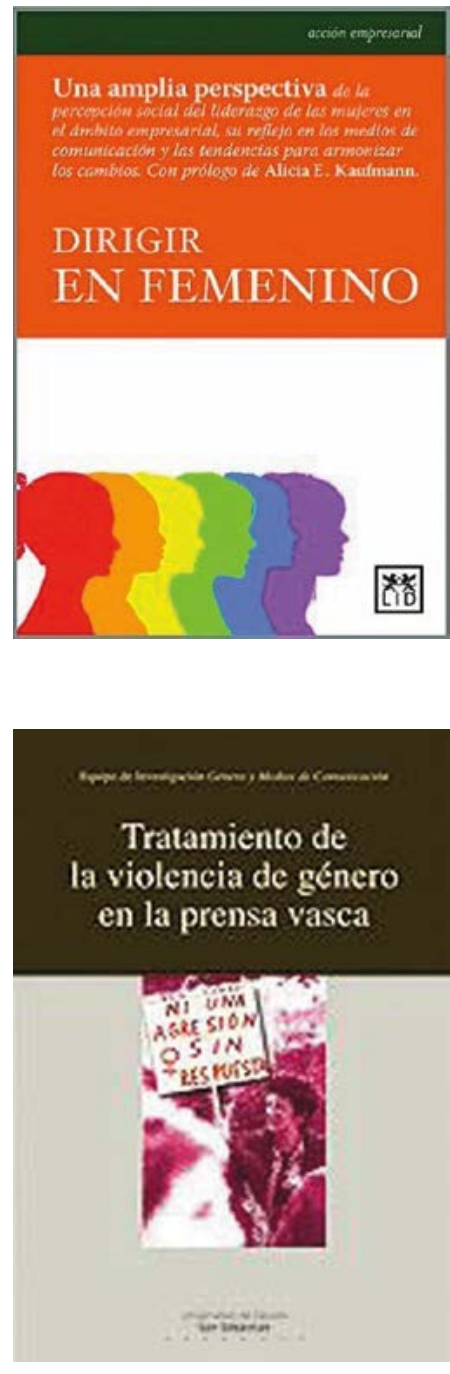

- Using a series of surveys conducted among the residents of Gipuzkoa, it was discovered that $70 \%$ were only aware of the problem of gender-based violence through the media. Our mental image of certain events is often down to the information that we obtain from the television, press, radio or Internet. Therefore, the way in which men and women are depicted is fundamental to see how our mental images are formed around gender.

- The term "gender" (gender studies, gender-based violence), which is defined in the book, goes beyond mere biological differentiation and refers to the cultural constructions, the social creation of ideas about what is appropriate and convenient for men and women. The gender concept can be defined as a set of beliefs, personal traits, attitudes, feelings, values, behaviour and activities that differentiate men and women through a social construction process that has several characteristics.

First, it is a historical process that has occurred at different levels: the state, the job market, schools, the media, the law, the family and through the interpersonal relations. Second, this process involves the hierarchisation of those traits and activities in such a way that greater value is attributed to those that are defined as male. The Institutes of Women and women's associations prefer the term "gender-based violence» to others to refer to the vio-

lence exerted by men against women.

GENDER: A set of beliefs, personal traits, attitudes, feelings, values, behaviour and activities that differentiate men and women through a social construction process.

- The recommendations proposed by the book for an appropriate treatment of gender-based violence in the press include focusing on this crucially important problem, as it is based on deep-rooted underlying cultural and social inequalities with information, rigour, and professionalism. 
It is time to call for in-depth documentaries and interviews, with the presence of experts in the topic in question and with the progressive training of the journalists tasked with this type of reporting
Allusions to love or romantic situations should be avoided. Each case should likewise not be discussed as an isolated accident or event. On the contrary, it is time to call for in-depth documentaries and interviews, with the presence of experts in the topic in question and with the progressive training of the journalists tasked with this type of reporting. Under no circumstances should the opinions of people who knew the abuser be included describing him as a great guy or which use the victim's behaviour, way of dressing, etc., to help to belittle her.

In December 2007, all the groups of the Basque Parliament managed to agree on a proposal focused on the analysis of gender-based violence in the Basque Country and put forward a series of proposal to advance equal rights between men and women, awareness-raising in society about the problem and improve the support that the victims receive from the authorities ${ }^{2}$.

A news report included the following information: «The report, which will be approved on Wednesday, apportions a key role to the media in the prevention of gender-based violence and calls for a committee to supervise their contents to avoid sexist messages and for them to follow the recommendations of the Treatment of Gender-Based Violence in the Basque Press book, published by Deusto University, when reporting» (El País, 16 December 2007)

- The improvement in the treatment of gender-based violence in the media is obvious and discriminatory or sexist reporting is been eradicated. This is where critical analysis can be carried out by studying past and present reporting to pinpoint the changes that have occurred in the different media until fairer treatment is achieved.

\subsection{Different media and their impact}

Media not only include television, the non-daily and daily printed press and radio stations, but also advertising, films, records, videos and the media based on new technologies (Internet: portal, e-newspapers, blogs and websites).

\footnotetext{
2 El País (2007). La ponencia sobre violencia de género logra el acuerdo de todos los grupos. Vitoria 16th December 2007. Available at: http://elpais.com/diario/2007/12/16/paisvasco/1197837599_850215.html https://www.google.es/webhp?sourceid=chrome-instant\&ion=1\&espv=2\&ie=UTF-8\#q=informe\%20 del\%20parlamento\%20vasco\%20sobre\%20violencia\%20de\%20g\%C3\%A9nero\%202007
} 
The main functions of the media are to:

- Disseminate information that allows the general public to acquire a perception of the world.

- Contribute to the social cohesion by the consensus that is established in the exchanging of information, providing company, entertainment and recreation.

- Meet knowledge and cultural demands.

- Legitimise the role performed socially by people, organisations and social movements.

- Legitimise the cultural, political and economic systems by means of disseminating rules, values, opinions and social attitudes.

- Encourage consumption and act as drivers of economic development and contribute to strengthening social identity ${ }^{3}$.

In this social identity, the perception of the gender roles and the role that men and women perform in political posts, in the different job categories and in the social classes, are strongly conditioned by the media and by advertising.

\subsubsection{Television}

Television is the most popular media in Spanish households. In 2015, television consumption was 237.7 minutes a day per inhabitant (over four hours), while this figure fell to 101.5 minutes in the case of radio and 10.5 when it came to reading the daily newspaper ${ }^{4}$. Television is a complex medium that offers a variety of programmes, but there are recurrent some aspects regarding the treatment of men and women, as noted by experts 5 .

1. Men and women are depicted differently in television. Men appear as professionals and are interviewed according to how they perform their work (politicians, sportsmen, businessmen), while women in the majority of cases appear as anonymous voices without any attention being paid to their social or professional qualities. In quantitative terms, the percentage of women interviewed is $26.4 \%$, while men account for $73.6 \%$ (Benárdez,

\footnotetext{
3 As José Luis Sánchez Noriega has indicated (2006) Historia del cine. Teoría y géneros cinematográficos, fotografía y televisión (Madrid, Libros Singulares, pg. 620).

${ }^{4}$ Statista (2015) Promedio de tiempo diario destinado a consumir medios de comunicación en España en 2015, por tipo. Available at: https://es.statista.com/estadisticas/491058/ consumo-diario-de-medios-de-comunicacion-en-espana-por-tipo/

${ }^{5}$ The information in this section is mainly taken from the book by Asunción Bernárdez titulado Propuestas para analizar la comunicación masiva con perspectiva de género (Madrid, Fundamentos, 2015).
} 
Is there a woman just as capable as the man interviewed who was not given the opportunity to speak? Is the woman being interviewed introduced by her merit or profession? Are the figures that represent the cultural, social, sport, political and economic elites always or nearly always male?
169). Those simple figures are sufficient for us to pay attention to reporting and we can ask ourselves some simple questions: Is there a woman just as capable as the man interviewed who was not given the opportunity to speak? Is the woman being interviewed introduced by her merit or profession? Are the figures that represent the cultural, social, sport, political and economic elites always or nearly always male?

Television advertising reproduces gender stereotypes in such a pronounced way that it gives no hint of the achievements that women are notching up in all areas, but rather, on the contrary, it categorises them in the traditional roles of housewife and mother. In a study conducted by the team ${ }^{6}, 275$ different adverts were analysed.

\section{If the main character of the advert appears as an expert, is it male? Do women appear as the main targets of the adverts on cleaning and looking after children? Is there a female image that must always meet the standards of beauty imposed by society?}

The analysis presented a picture where men are the owners of businesses, the ones who work, who study, the sportspersons and the experts in different fields. In the adverts, there is a main male character who performs these roles and work activities, while there is also a female character in all of them who appears as a passive companion, as a spectator, as a colleague or a person benefitting from the explanations of the expert. The results obtained in this study project a message for young people and adolescents regarding their future expectations in the home and work settings that are hugely unbalanced in gender terms. Some simple questions that must be raised in this area when watching the television adverts are as follows: If the main character of the advert appears as an expert, is it male? Do women appear as the main targets of the adverts regarding cleaning and looking after children or in a domestic context? Is

\footnotetext{
${ }^{6}$ "Young People and Televised Advertising. Job World Projections» Mujeres, formación y empleo: realidades y representaciones/Emakumeak, prestakuntza eta enplegua: errelitateak eta irudipenak Donostia-San Sebastián, Gipuzkoa Provincial Council, 2011)
} 
Those areas where the female presence is greater, but where this female depiction is associated to the traditional distinction between the woman as a "victim" and as "dangerous", so that the participants are subject to sexist moral opinion, have to be observed with care. How are the men and women that take part in those programmes treated by the audience? there a female image that must always meet the beauty standards imposed by society?

2. As regards entertainment programmes such as reality shows and talk shows, a desire to break down the barriers between the public and the private ones can be seen. Compared to the "serious» programmes that are usually presented by men, women here predominate as presenters, as participants and in the audience.

The fundamental question must be the one raised by Asunción Bernárdez: "What type of depictions of being female do those programmes offer?» and the answer is as follows: "The trend is for highly stereotyped female models: a somewhat mindless and self-sacrificing housewife; the femme fatale that makes no man happy; the devoted mother without her own expectations; the silly teenage girl; the uneducated, but well-meaning small-town woman, etc.» (Bernárdez, 183). These are areas where the female presence is greater, but in which this female depiction is associated with the traditional distinction between the woman as a «victim» and as "dangerous», so that the participants are subject to sexist moral opinions. How are the men and women that take part in those programmes treated by the audience?

3. There are many other areas that cannot be analysed here, such as television series, sports programmes, etc. Advances are being made in all fields and women are breaking into traditionally male spaces and starting to make themselves heard in areas where they were previously banned. Yet inequality still prevails. 


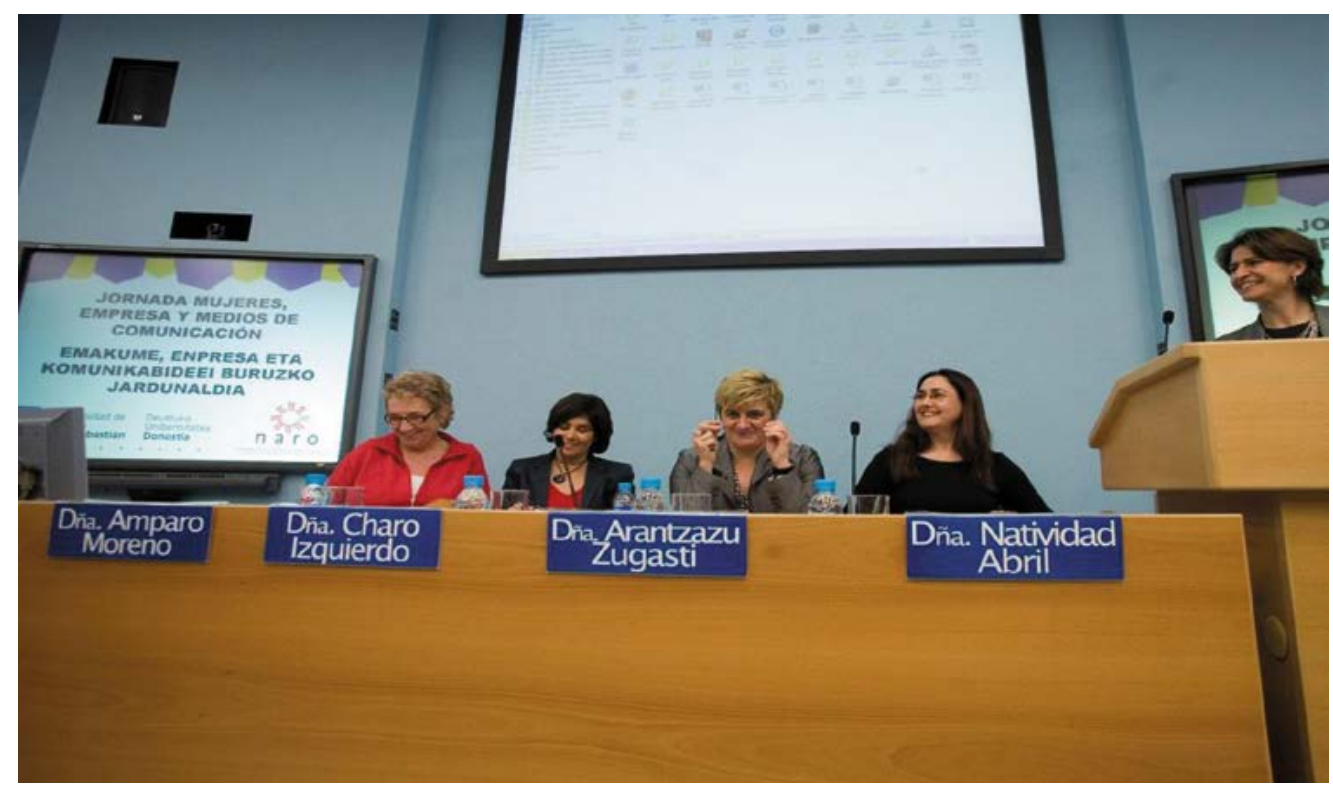

Symposium on Women, Business and the Media, DU-San Sebastián

\subsubsection{Press}

The press was the part of the media analysed to the greatest extent by the team. In all the published books, content, qualitative and quantitative analyses have been conducted and all the genres studied: reporting, interviews and documentaries, opinion and illustrations. In keeping with the critical analysis of the discourse based on the theory of Teun A. van Dijk, we believe that journalistic discourse is not objective as it always contains an implicit ideology. According to the research conducted by the team:

- Women occupy less space in the prestigious sections such as politics, economy or international news. They appear as experts or representatives in very few cases. As regards the treatment of men and women in spheres of power such as politics and economics, it is useful to turn to the report entitled Spain. Global Media Monitoring Project 2010. National Report. It provides huge amounts of data on the presence of women in the media. In the 315 news items monitored, women account for only $23 \%$ of the people that appear in the reporting.

The reports indicates that the presence of men and women in the various reporting topics is in reverse order, in other words, where there is greater male presence the lack of women is more obvious and vice versa. For example, while the subject of childhood and youth is where there are 


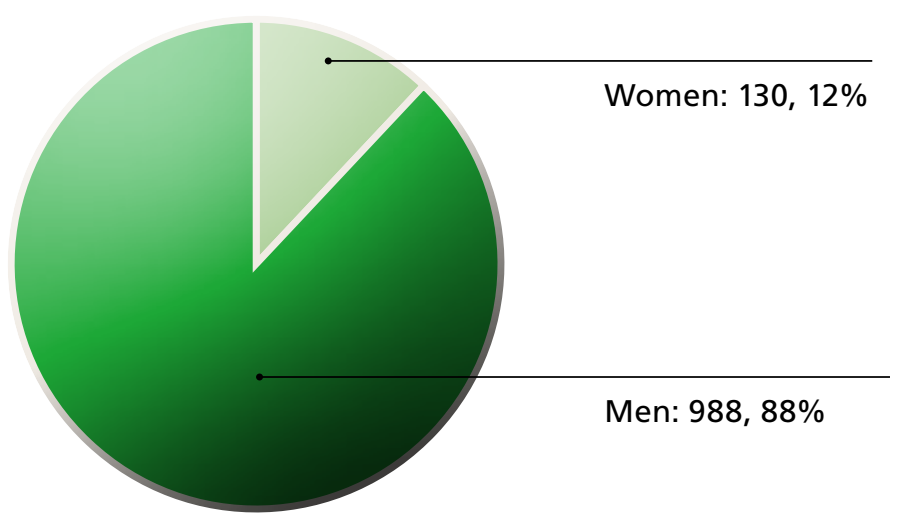

The role of expert is most

frequent among men

(91\%), while women are

only asked for their expert

opinion in $9 \%$ of cases

most mentions of women, it is in last place as regards men. We have another example where female presence is in last place: Politics and economics are areas where, by contrast, there is the greatest percentage of male appearances. The descriptions of women as politicians stand at $25 \%$. As regards the role played by the men and women mentioned in the news, the role of expert is most frequent among men (91\%), while women are only asked for their expert opinion in $9 \%$ of cases. The position of spokesperson is another aspect which stands out in stark contrast, where $82 \%$ of the people who appear are men and 18\% women.

It is fundamental for girls to have references in the spheres of leadership and if the treatment of those women is demeaning, disrespectful or discriminatory, the message transmitted deters young women and prevent economic and social progress.

Taking all the press analysed (El País, El Mundo, El Diario Vasco, Noticias de Gipuzkoa, Gara and Berria) as a whole, the presence is $12 \%$ women compared to $88 \%$ men in the ranking of political figures that most appear in the press.

M.J. Korkostegi 

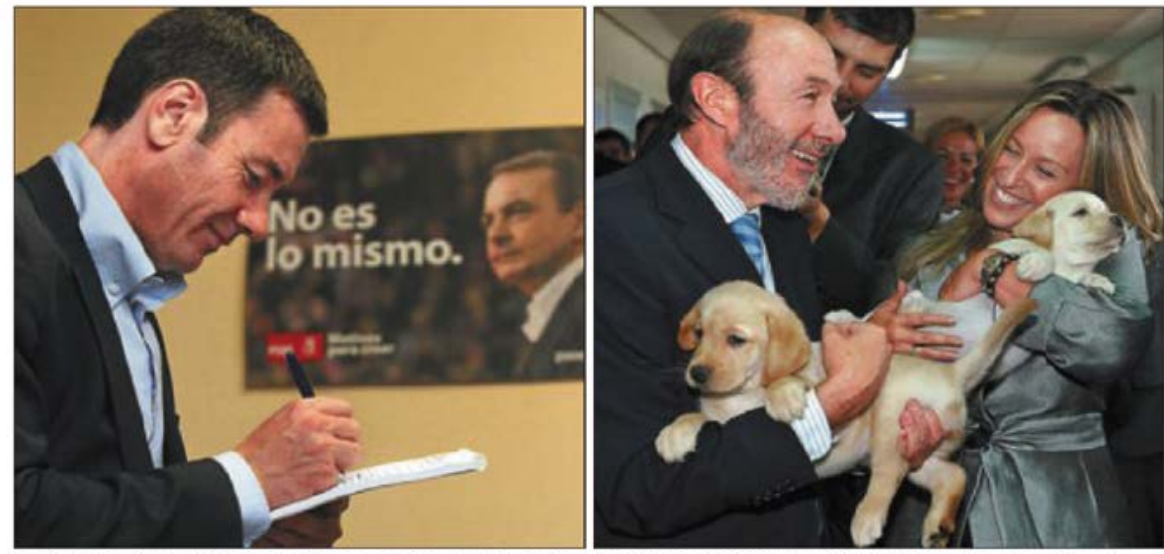

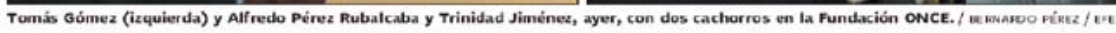

- When women appear as key players or representing politics or of other spheres of power, reference is often made to their appearance, to their family and private life, to their clothes or to other issues not directly linked to their professional performance. There is a trend to refer to women by their first name rather than by their surname, as is the case with men. A clear example is given in the book entitled Representaciones de las mujeres políticas en la prensa [«How Women are Depicted in the Press»] when it analyses the different treatment of Trinidad Jiménez and of Tomás Gómez during the Madrid Autonomous Region Primaries, in October 2010. Raúl del Pozo in the article entitled «ZP: Defeat in Callao» (EI Mundo, 4 October 2010) begins as follows: «The Trini, with her Schweppes smile, did not win Callao, which is a defeat for ZP» (bold and italics in the original). It later refers to what she is wearing ("cream

Women accounted for only $28 \%$ of the total subjects and sources in the press news items and the radio and television reporting, and 33\% in the digital newspapers and Twitter. As subjects of the news items, women always account for less than $30 \%$ of the total: $28 \%$ in press, $26 \%$ in radio and $29 \%$ on television jacket, jeans, holding her sunglasses»). The episode of the Madrid primaries hyped up the sexist treatment of the candidate - and the ensuing reaction and public condemnation - following Alfonso Guerra's comment on 6 October, when he said: «Mr. Tomás Gómez and his supporters won and Miss Trini and her supporters lost. That is obvious and any other interpretation is skirting the issue».

- The Global Media Monitoring Project (GMMP) is the most established and broadest research worldwide that 
addresses the subject of gender in the media. In 2015, a total of 452 news items - 65 of which were in printed daily newspapers, 65 on the radio, 88 on television, 61 in digital newspapers and 173 tweets - were analysed nationally. Women accounted for only $28 \%$ of the total subjects and sources in the press news items and the radio and television reporting, and 33\% in the digital newspapers and Twitter. As subjects of the news items, women always account for less than $30 \%$ of the total: $28 \%$ in press, $26 \%$ in radio and $29 \%$ on television. Concerning the topics, women are a minority in all reporting except those related to crime and violence where they account for $51 \%$ of the total. With respect to women as sources for the reporting, their largest presence is as sources of public opinion (43\%), sources of personal experience (37\%) and subjects of the news items (35\%). Their lowest percentage is as experts (9\%). Therefore, when the media or producers have to choose an expert for the news, they exclude women as experts and commentators.

Gender designation way in which the leading political figure is designated in the headline according to their gender

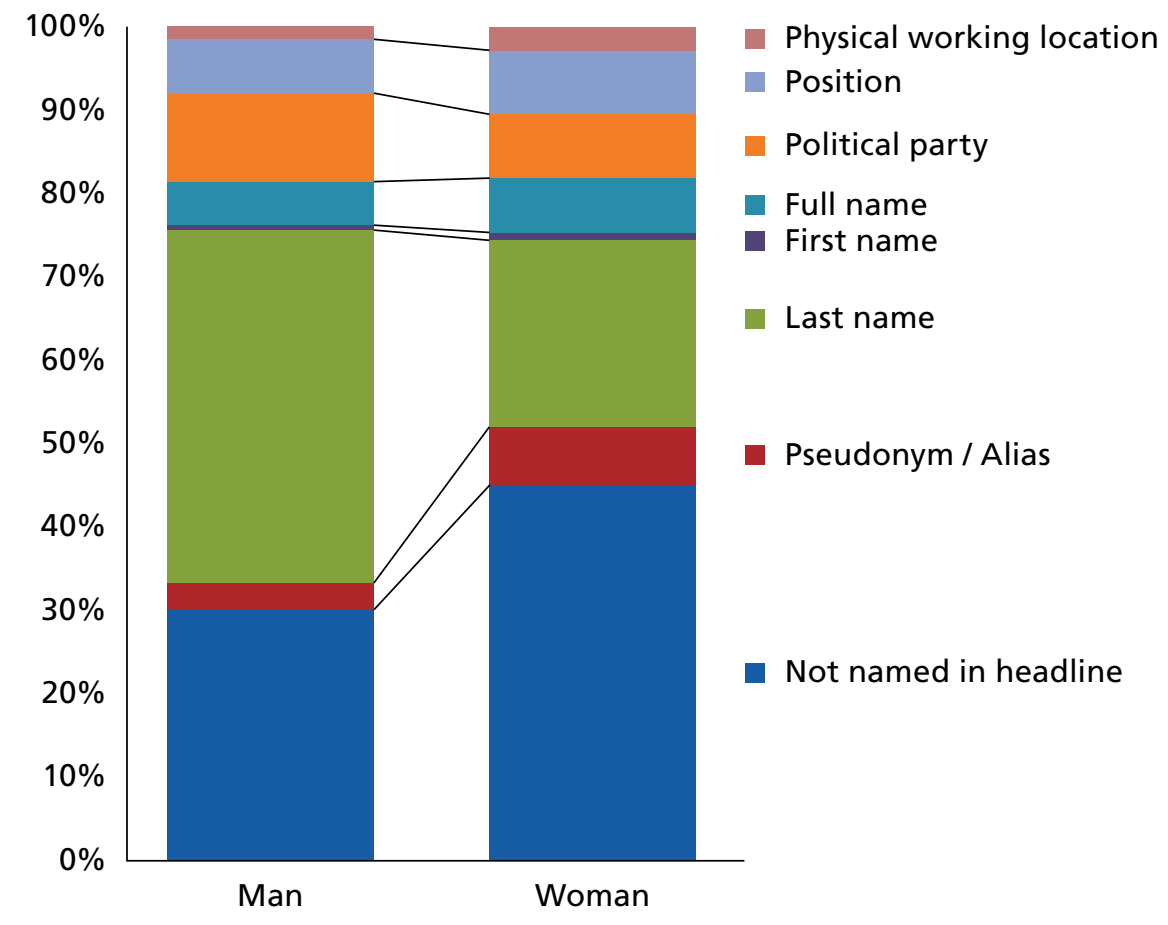

Source: Berasategi, Representación de las mujeres políticas en la prensa, (2010) 
- It is easy to see how all this information can lead to a series of analysis in the different educational stages for children and young people to be aware of the gender depiction that appear every day in the various media and acquire the skills and critical capacity to know how to understand them, question them and be capable of choosing their own information channels or, at least, of not immediately accepting reporting with stereotypical or sexist traits.

\subsubsection{Internet and Social Media}

Information and Communication Technologies (ICT) have become the main communicators of information, knowledge and entertainment. As occurs in other media and information channels, the so-called gender gap also exists here, as the International Telecommunication Union (ITU) estimates that there are nearly 250 million fewer women with access to the ICT than men in the world. Three are countries where there is a balance between the access of men and women to the Net (such as Iceland, with $96.9 \%$ for men and $95.5 \%$ for women) and others with a marked inequality (such as India or Egypt). Spain is mid-range with an average of $72.4 \%$ of men compared to $67.2 \%$ of women who access the Net (see Bernárdez, 222).

There is another type of gender dig-

Internet has become a very visible place for the gender struggles and even though misogynistic attacks are frequent, the complaints and the contempt for those people who produce that type of messages have become very powerful ital breach. Women are mainly Internet users, but there is a great inequality regarding their participation as experts in technology, as their presence as programmers and website and software designers is marked by the male dominance of areas in education, research and employment related to engineering and technology.

The main concern regarding the formats and contents of the Net and of social media lies in the fact that, in the same way as the other media studied,

they have been developed on a patriarchal depiction model and are based on a series of value that are often harmful for the images of women. The new technologies are burdened down by patriarchal models noted for discrimination, but in turn have the potential of being a much more open world and with a strong participation component that allows inequality to be combated. Remedios Zafra stresses the resistance capacity that must be developed for the Net not to be just a means of information and economic exchange where the stereotypes are perpetuated. 
Another type of digital gender gap regarding the participation of women as experts in technology, programmers and program and website designers is related to the male-dominated engineering and technology fields in education, research and employment.

Teaching adolescents and young people must be based, as Asunción Bernárdez points out, on the use of the Net to generate new questioning and creative activities and not to resign ourselves to be mere passive users, by fostering critical reflection and acting against inequality (Bernárdez, 231). One of the current concerns is related to social media and the reproduction of the control and violence system that exists in society.

Internet has become a very visible place for the gender conflicts and even though misogynistic attacks are frequent, the complaints and the contempt for those people who produce that type of messages have become very powerful. Education in this medium is fundamental and the ability to act is one of the strengths that foster intervention to construct more equal identities.

\subsubsection{Advertising}

The messages of advertising language, therefore, rely on activating the individual desire through discourses that transmit values that are unconditionally accepted by the masses, such as safety, love, beauty or social success
As has already been pointed out, advertising continues to be a sphere in which the gender roles have a marked impact. Why do stereotypes persist in advertising more than in any other sphere? Male and female experts alike attribute this resistance to "cognitive saving strategy" (Bernardez, 84), in other words, the stereotype functions as a mainstreamed cultural model when depicting men and women; in the case of the advertising discourse, this stereotyped depiction of women and men is commonly associated to collective values linked to the immediate emotional gratification, where the individual desire converges with the dominant collective imagination. Advertising does not seek to depict the reality as it is, but rather to trigger the desire of the individuals and provoke emotional reactions that drive the consumption of a certain product, whether it is a car, life insurance, household appliance or a political party. The messages of advertising language, therefore, rely on activating the individual desire through discourses that transmit values that are unconditionally accepted by the masses, such as safety, love, beauty or social success. Consequently, it is an 


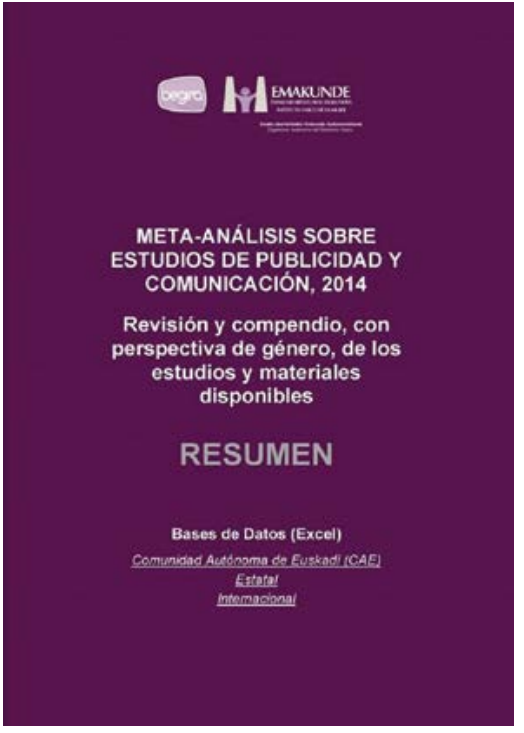

Estudio llevado a cabo por el

equipo para Emakunde en 2014

extremely powerful instrument to transmit values and conduct that is consumed uncritically and which intensely penetrates the cultural imagination.

It is, therefore, not strange that much of the work carried out on gender treatment in the media in recent years has focused on analysing and denouncing advertising discourse. The analysis of media and advertising carried out by this research group in $2014^{7}$ for BEGIRA (Advisory Committee for Non-Sexist Advertising) of the Basque Institute of Women - Emakunde revealed that advertising continues to corner much of the media analysis. National government, international institutions such as the Gender Monitoring Media Project (GMMP) that has been publishing reports every five years since 1995, and supranational institutions such as the European Union by means of resolutions and recommendations of the European Parliament and the European Council, have shown their interest and concern regarding the persistence with which traditional gender models are used in the advertising world and in media production, particularly in the case of television, and they strive to establish codes of conduct for all member countries. Self-regulation is advocated so there will be a gradual correction of the disparity between the more equalitarian and changing reality and advertising and media that stubbornly continue to reproduce obsolete stereotypes and are reluctant to incorporate new models and new voices. Attention has thus shifted not only to the products coming out of advertising and media, but also on the people who create them and on educating a critical audience able to discriminate.

By means of example: an analysis of three advertising commercial

In the world of Internet and in television advertising, along with the repetition of sexist stereotypes and the escalation of the role of women as compulsive consumers, the possibility of actively creating new models of women in keeping with reality is also contemplated.

\footnotetext{
${ }^{7}$ María Pilar Rodríguez, María Jesús Pando, Esther Ferrer and Miren Berasategi: Meta-análisis sobre estudios de publicidad y comunicación, 2014. Revisión y compendio, con perspectiva de género, de los estudios y materiales disponibles (Vitoria-Gasteiz, Emakunde, 2014).
} 


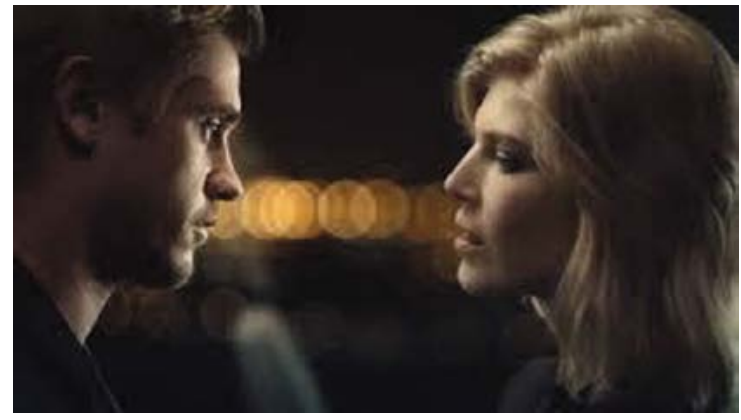

Three examples of advertising commercials broadcast by TV that illustrate some perceptions associated with stereotypes and discrimination are set out below. In the first example, stereotypes and greater sexualisation of the female body persist, particularly regarding products associated to beauty and sexual attraction. Second, a model is presented of what could be called "soft sexism" and which is interesting as it reveals certain perplexity in the construction of new female models, who are more powerful, but trapped in old prejudices. Third, a non-sexist advertising model where gender roles are exchangeable is considered.

The first example comes from a now traditional area where hypersexualisation and stereotypes stubbornly persist. That is the world of cosmetic and perfume advertising. The commercial is the Diesel Bad one from the 2016 autumn season ${ }^{8}$. This male fragrance uses a micro-story to show two models of male and female conduct that are markedly different and sadly rooted in the clearest black and white terms. They are stereotypes that supposedly had been eradicated years ago and which are rooted in the classical tradition of the wandering hero whose life is steeped in adventures, dangers and frenzied experiences, in sharp contrast with the quiet and submission of a hypersexualized female figure whose fate is to accept the wild character of her beloved and submissively await his return. The man promises to love her if she accepts his free and nomad status: male action vis-à-vis female passivity; his voice vis-à-vis her silence; assertiveness and determination vis-à-vis submission and acceptance; freedom vis-à-vis dependency. This polarisation is likewise captured in the sensual beauty of the blonde model, compared to the vital and athletic appearance of the male model, in an absolutely primary semiotic association of discourses, images and colours.

The second example presents a more problematic case. Even though advertising now often strives to provide an image of women closer to their family and professional roles, the female body and sexuality can still be seen to continue marking the advertising messages. They are often messages aimed at younger people, where the traditional stereotypes associated to women are mixed and confused with a type of vindication that seeks to be associated with liberating and feminist values, but which ends up leading to openly sexist models. One such case is the commercial that the Desigual brand released on Mother's Day 2014'. In this commercial, a young woman who is trying on a tight Desigual dress, uses a pillow too look pregnant

\footnotetext{
${ }^{8}$ https://www.youtube.com/watch?v=bX9EV3qZAe0

${ }^{9}$ https://www.youtube.com/watch?v=8D60FJPvyRM
} 

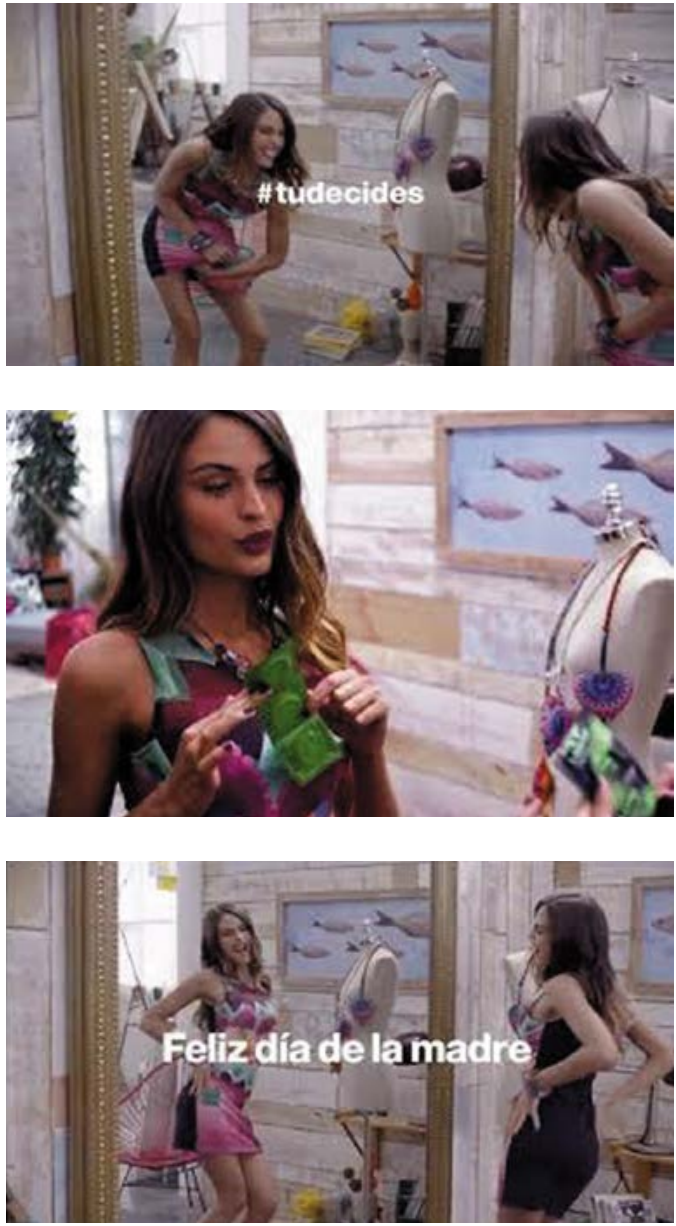

while she happily and coquettishly looks at her pregnant self in the mirror. Then, after sensually sucking on a pin, she uses it to make a hole in a condom, as the initial slogan of the "You Decide» campaign turns into "Happy Mother's Day». Why did this commercial cause so much fuss? It is certainly down to the people behind the commercial wanting to generate impact and visibility, inherent to the primary function of advertising, but undeniably the campaign, already preceded by other similar adverts, sought to also create a fresh and original story of a flirty, funny, sexy young woman who controls the strings of her life, of her body and of her destiny: she decides if she wants to be a mother and her action is clearly aimed at giving motherhood a sensual, funny, sexy and entertaining touch. However, the story encountered a handful of stereotypes along the way that made the so-called tribute to motherhood and to women's ability to decide into a type of insulting frivolity for women, and of irresponsibility for young men and women who want to be on a free and equal footing in their sexual relations. The commercial reinforce the stereotype that the first attribute of a woman is to be attractive and sexy, and that she will not fail to resort to tricks and deceit, always related to her sexuality and her body, to get her own way.

Thus, freedom of choice is confused with deceitful, frivolous and irresponsible behaviour that helps to perpetrate the great cliché that has traditionally defined women as being malicious and tricksters, where men are the helpless 

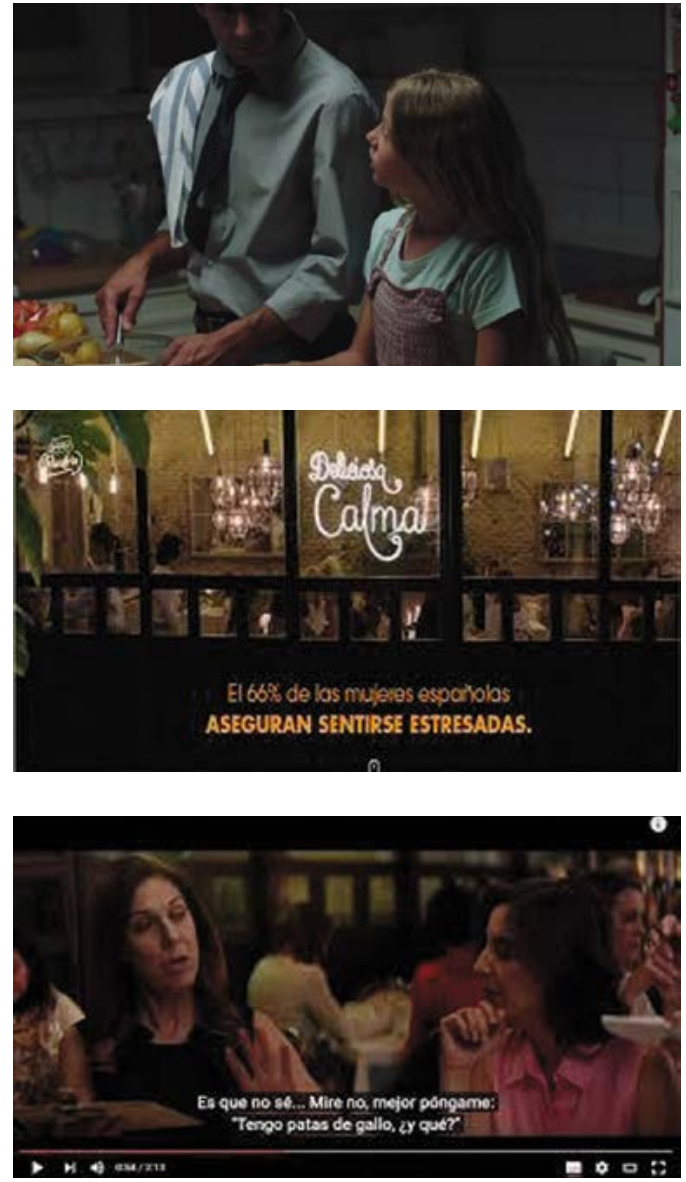

victims of their deceit. In its desire to transgress and be provocative, the commercial not only does not offer a liberating picture or women, but rather objectifies them even further, by linking motherhood to a mere "look» and freedom to a frivolous and deceitful nod to sex. What this commercial depicts, ultimately, regarding the evolution of how gender is depicted is the confirmation that, despite the models changing, a imaginary power of femininity associated to the body, sexuality and beauty underscores any depiction.

The changes that have occurred in the advertising image of women in recent years, who have shifted from being the submissive object of men to a model of a more independent women, who is active and assertive in her sexual identity, are examined by authors such as Rosalind Gill, who questions how this supposed empowered operates in these new figures within the heteronormative relations and how those shape the relations of power. The sexual activity of those women thus functions as a type of regulation that allows the female perspective to fit into a neo-liberal and post-feminist framework that, ultimately, continues to call for this new model of women to carry on being not only beautiful, but also sexy, sexually experienced and "willing».

Compared to those models, commercials relating to household consumption are where the greatest progress perhaps has been made in the reviewing of the roles traditionally allocated to men and women. And this is where we come to the third example. In these cases, it is no longer about the values associated to beauty, success and sexual attraction, but rather about those related to safety, happiness and family life. Some such examples are Ikea's 2016 «It's dinner time!» commercial ${ }^{10}$, where the family setting at dinner time becomes a place for dialogue, equality and tolerance; or Campofrio's now famous 2016 «Delicious

\footnotetext{
${ }^{10} \mathrm{https}: / /$ www.youtube.com/watch?v=-ER2jqVE6jQ
} 
Doing the critical exercise of exchanging female and male figures in advertising narratives helps to diagnose the level of sexism in an advertising commercial
Calm ${ }^{11}$, where real everyday women representative of a social middle class collectively reject the tyrannies of imposed stereotypes and demand the right to get old, not to fit the thin prototype, or to be imperfect.

In short, the critical consumption of advertising - and, therefore, the rejection of discourses that systematically belittle or undermine women, who hypersexualise them or strip them of authority is fundamental for the advertising industries to progressively construct male and female models representative of the

social roles that they perform in modern societies in a more equal representation. In the case of the advertising aimed at children and adolescents, this principle is even more essential, as it helps to construct easily assimilated collective imaginations and to model behaviour patterns. The critical exercise of exchanging female and male figures in advertising narratives helps to diagnose the level of sexism in an advertising commercial.

\section{RECOMMENDATIONS}

Educate children and young people in the main formats of the media in direct connection with the basic principles of gender studies.

Develop analysis skills and critical thinking to detect and identify the stereotypes that allow the transmission of inequality in the media.

Analyse the images, information and news, and reject any depiction of women that hinder or prevent their professional and social development.

11 https://www.youtube.com/watch?v=aZSSiYvgxsU 
Work on the development of a citizen critical awareness that actively contributes to a fairer and more equalitarian depiction of women by means of identifying and protesting discriminatory and stereotyped models.

Work on the inclusion of female models that reflect the diversity of their contribution in the professional field, while avoiding victimisation and reproduction of stereotypes in order to contribute to a fairer society.

\section{Bibliography}

Bernárdez, Asunción (2015). Mujeres en medios. Propuestas para analizar la comunicación masiva con perspectiva de género. Madrid, Fundamentos

Gender and Media Research Team (2006). Tratamiento de la violencia de género en la prensa vasca. San Sebastián, Deusto University

Gender and Media Research Team (2011). Mujeres, formación y empleo: realidades y representaciones / Emakumeak, prestakuntza eta enplegua: errelitateak eta irudipenak. Donostia, Diputación Foral de Gipuzkoa.

Gill, Rosalind (2007). Gender and the Media. London, Polity Press

Korkostegi, Pando, Rodríguez, Sanz, eds. (2009). Dirigir en femenino. Madrid, LID

López Díez, Pilar (2004). "La mujer, las mujeres y el sujeto del feminismo en los medios de comunicación» en Manual de información en género. Pilar López Díez (ed.) Madrid: IORTV (RTVE) and Institute of Women

Rodríguez, Maria Pilar, ed. (2012). Representaciones de las mujeres políticas en la prensa. Bilbao, Deusto University Publications

Rodríguez, María Pilar; Pando-Canteli, María Jesús; Ferrer, Esther, and Berasategi, Miren (2014). Meta-análisis sobre estudios de publicidad y comunicación, 2014. Revisión y compendio, con perspectiva de género, de los estudios y materiales disponibles. Vitoria-Gasteiz, Emakunde.

Sánchez Noriega, José Luis (2006). Historia del cine. Teoría y géneros cinematográficos, fotografía y televisión. Madrid, Libros Singulares

Sanz, Begoña, ed. (2015). Las mujeres deportistas en la prensa: los Juegos Olímpicos de Londres 2012. Barcelona, UOC 


\section{Biographical notes}

\section{María Pilar Rodríguez}

María Pilar Rodríguez is a Professor at the Communications Department at Deusto University. She holds a PhD from Harvard University (Cambridge, USA). She lectured at Colombia University (New York, USA) until 2002. She has published widely on literature, films, culture and gender studies. María Pilar is the Lead Researcher of the Communications team, which is recognised by the Basque Government. She is a member of the editorial board and evaluator of academic journals such as Bulletin of Hispanic Studies, Hispanic Review and European Visual Cultures. She regularly lectures at North-American universities. She has been granted three six-year research periods by the CNEAI. In 2015, she was appointed to the Koldo Mitxelena Chair by the Basque Government.

\section{María J. Pando Canteli}

María J. Pando Canteli is a Professor at the Modern Languages and Basque Studies Department at Deusto University, where she lectures in Gender Studies, Contemporary Literature in English and European Studies, to students on degree, master's and PhD courses. She has a PhD in Language and Literature and she has also taught at the University of the Basque Country and at Santa Clara University (USA). She was a Fulbright scholar at Stanford University (USA) between 2008 and 2009 and a fellow of Folger Shakespeare Library (USA). Gender studies are at the heart of her research and it focuses, on the one hand, on European cultural and literary relations in the 16th and 17th centuries, and, on the other hand, on communication studies. María J. Pando has published widely in the fields of Gender and Communication and in the sphere of cultural studies of early modernity.

\section{Miren Berasategi}

Miren Berasategi graduated in Humanities: Communication (Deusto, 2004), has a Master's Degree in the Information and Knowledge Society (UOC, 2008) and is a University Expert in Advanced Methods of Applied Statistics (UNED, 2011) and in Multivariate Statistical Techniques (UNED, 2011). She is currently a contracted lecturer at Deusto University, where she teaches at the Donostia-San Sebastián campus. Miren's teaching activity focuses on the Degree in Communications, where she teaches the following subjects: Projects for the Web and Messages for the Web. Miren belongs to the Communications research team recognised by the Basque Government and she is currently working on her PhD thesis on the university teaching of data journalism. 



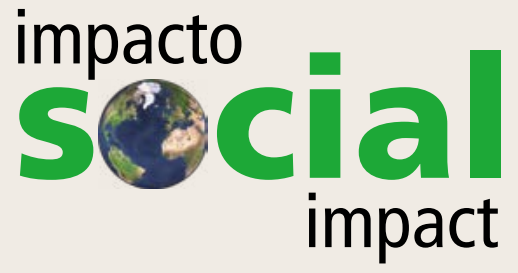

